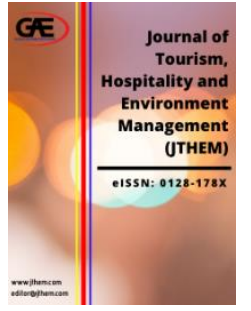

\author{
JOURNAL OF TOURISM, \\ HOSPITALITY AND \\ ENVIRONMENT MANAGEMENT \\ (JTHEM) \\ www.jthem.com
}

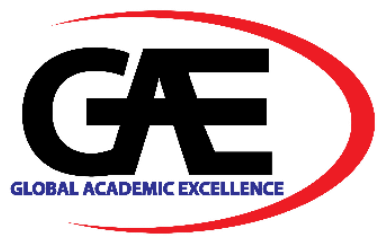

\title{
THE IMPACT OF COMPETITIVE INTELLIGENCE ACQUISITION AND UTILIZATION ON HOTELS' PERFORMANCE: EVIDENCE FROM MALAYSIA
}

\author{
Akram Mufareh Alshammakh ${ }^{1 *}$, Adi Anuar Azmin ${ }^{2}$
}

1 Faculty of Applied and Human Sciences, Universiti Malaysia Perlis, Malaysia, and Thamar University, Dhamar, Yemen

Email: alshamakha@yahoo.com

2 Faculty of Applied and Human Sciences, Universiti Malaysia Perlis, Malaysia

Email: adianuar@unimap.edu.my

* Corresponding Author

\section{Article Info:}

Article history:

Received date: 15.09 .2021

Revised date: 15.10 .2021

Accepted date: 26.10 .2021

Published date: 01.12.2021

\section{To cite this document:}

Alshammakh, A. M., Azmin, A. A. (2021). The Impact Of Competitive Intelligence Acquisition And Utilization On Hotels' Performance: Evidence From Malaysia. Journal of Tourism Hospitality and Environment Management, 6 (26), 01-26.

DOI: $10.35631 /$ JTHEM.626001.

This work is licensed under CC BY 4.0

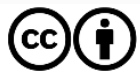

\section{Abstract:}

Acquisition and frequency utilisation of Competitive Intelligence (CI) are critical strategic activities designed to assist firms in evaluating emerging trends in their business environments, major and potential threats, capabilities, and competitions for businesses today, particularly in the tourism and hotel sectors. However, there is still ambiguity about the impact of competitiveintelligence acquisition (CIA) and utilisation (CIU) on firms' performance, particularly for the hotel industry in a developing country such as Malaysia. Thus, the purposes of this research are to define the nature of CI practice in Malaysian hotels, and to illustrate the relative importance of various CIA types and sources to marketing managers in Malaysian hotels, moreover, to investigate the impact of CIA and CIU on the financial and non-financial performance of Malaysian hotels. A quantitative research design was adopted in this study. To obtain the necessary data for analysing the hypothesised model of the study, 505 questionnaires were issued to marketing managers in member hotels of the Malaysian Association of Hotels (MAH), and a total of 184 analyzable questionnaires were gathered, with a response rate of $34.44 \%$. The research data were analysed using partial least squares structural equation modelling and statistical package for social sciences "SPSS". Despite that half of the responding hotels practiced CI informally, and many of these hotels began practicing CI five years ago, the study found that hotel marketing managers have high and medium interest levels for most types and sources of CI in Malaysia, these five CIA's types were the most important: (1) competitors, (2) customers, (3) human resources, (4) socio-cultural, and (5) Global. As well, these five CIA's sources were the most important: the internet and extranets, (2) customers, (3) electronic information services/intranets, (4) 


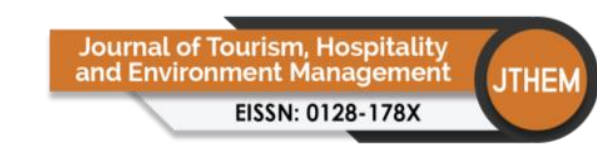

Volume 6 Issue 26 (December 2021) PP. 01-26

DOI 10/35631/JTHEM.626001

business associates, and (5) newspapers and periodicals, and industry trade associations. Furthermore, the results indicate that CIA and CIU had a positive and significant impact on hotels' performance, but CIU has the most effect. These findings enrich those in positions of power like owners, managers, and practitioners, as well as academicians, with greater knowledge of the relationship and influence of CIA and CIU on firms' performance, particularly for hospitality and tourism firms.

Keywords:

Hotel Performance. Competitive Intelligence Acquisition, Utilization. Hospitality. Tourism. Malaysia

\section{Introduction}

Tourism has developed into a significant sector in a number of countries, and according to the United Nations World Tourism Organization, tourism ranks fourth among export categories globally, behind fuel, chemicals, and food (Mohammed et al., 2017; UNWTO, 2018; Ahn \& Kwon, 2020). Tourism is one of Malaysia's significant prospective growth sectors in the service economy, and it is the country's second largest source of foreign money (Sin \& Jusoh, 2019; Yadegaridehkordi et al., 2020; Ahn \& Kwon, 2020). Where it generated 3.4 million employments in 2017 and 15.2 percent of Malaysia's GDP in 2019, Malaysia also welcomed 26.10 million tourists in 2019 and generated RM 86.10 billion (Tourism Malaysia, 2020). The hotel industry is a critical component of tourism and thus one of the most promising sectors in Malaysia, where Malaysia offers a diverse range of accommodation options to visitors, including hotels, individual guest houses, motels, self-catering, and other private accommodation. Additionally, by the end of 2019, Malaysia had 4,826 hotels with 315,969 rooms (Tourism Malaysia, 2020). As a result, effective tactics are required to enable the Malaysian hotel business to overcome the strong competition.

Despite the Malaysian government's emphasis on tourism, as demonstrated by their 2020 vision of 36 million tourists, records show a fall in tourist arrivals in Malaysia from 27.44 million in 2014 to 26.10 million in 2019. (Yadegaridehkordi et al., 2020; Tourism Malaysia, 2020). Additionally, prior research has demonstrated that the hotel sector operates in an aggressive competitive environment and is subject to environmental turbulence, resulting in a decline in occupancy rates, with the occupancy rate for Malaysian hotels falling from 69.7 percent in 2014 to 58.8 percent in 2019. (Sin \& Jusoh, 2019; Yadegaridehkordi et al., 2020; Tourism Malaysia, 2020). As a result, in order to remain competitive in such a challenging industry, hotel managers and executives should leverage appropriate strategic practices, such as Competitive Intelligence $(\mathrm{CI})$ practice, to help them remain in the market and thrive (Yap et al., 2014; Yan-Li \& He-feng, 2016; Salguero et al., 2019; Köseoglu et al., 2020).

Competitive intelligence (CI) is a systematic, targeted, timely, and ethical process that focuses on collecting, synthesising, and analysing data from the firm's internal and external environments and disseminating it to key decision makers (Calof et al., 2018; Oraee et al., 2020; Madureira et al., 2021). CI has emerged as a vital aspect in maintaining competitive advantage, integrating company strategy and environment, and developing and executing strategy (Calof et al., 2018; Collovini et al., 2020; Madureira et al., 2021). Effective CI practises will lead to successful alignment of competitive strategies with environmental standards, as well as outstanding performance (Yap et al., 2014; Hendar et al., 2020; Calof \& Sewdass, 2020; Silva, 2021; Hanif et al., 2021). When it comes to evaluating competitors and building tactical 


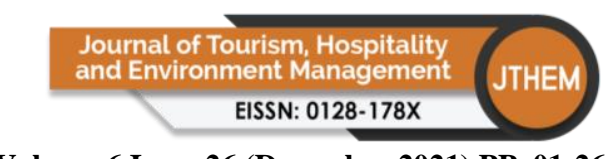

Volume 6 Issue 26 (December 2021) PP. 01-26 DOI 10/35631/JTHEM.626001

and strategic plans, CI is a must-have (Oraee et al., 2020). CI is utilised in various areas relating to strategy in enterprises, such as support for strategic decision-making, early warning of opportunities and dangers, competitor assessment and tracking, and support for strategic planning and implementation (Oraee et al., 2020; Calof \& Sewdass, 2020; Madureira et al., 2021). As a result, $\mathrm{CI}$ is an invaluable resource for strategic planning and other operations, as it provides information on the activities of current and future competitors (Hendar et al., 2020; Calof \& Sewdass, 2020; Silva, 2021). In this regard, CI has established itself as one of the most effective strategic practises for enhancing an organization's performance and competitive advantage (Maritz \& du Toit, 2018; Oraee et al., 2020; Calof \& Sewdass, 2020; Madureira et al., 2021; Hanif et al., 2021). Additionally, according to Yan-li \& He-feng (2015), Yan-Li and He-feng (2016), and Salguero et al. (2019), the hotel industry is in desperate need of CI, particularly in the era of big data, where a more comprehensive practise of CI will assist hotel managers in making more informed and prudent marketing decisions by providing them with high-quality, timely, and comprehensive information, which can result in improving performance.

Despite the critical significance of CI in firm survivability, its application has been diverse. Some firms employ CI on a tactical basis, while others employ it on a strategic level, and there is also considerable variation in the success of CI implementation between companies and sectors (Yan-li \& He-feng, 2015; Köseoglu et al., 2016; Søilen, 2017; Cavallo et al., 2020; Silva, 2021). Furthermore, despite the fact that competitive intelligence is a multidimensional strategic practice manifested in competitive intelligence acquisition (CIA), competitive intelligence process (CIP), and competitive intelligence context (CIC), the majority of prior research has concentrated on the CIP and CIC (Saayman et al., 2008; Seyyed-Amiri et al., 2017; Calof, 2017; Calof et al., 2018; Oraee et al., 2020; Hanif et al., 2021). Thus, prior research has recommended investigating the relationship between CIA and organisational performance, given the significance of CIA, which refers to the variety of types of CIA (e.g., competitors, consumers, suppliers, technology, economy, and so on), and the sources of CIA (e.g., customers, suppliers, internet, media, and so on) that used to obtain information about a company's internal and external environment and elucidating the importance and frequency of utilising the various types and sources of CIA (Yap et al., 2014; Yap et al., 2018; Asghari et al., 2020; Oraee et al., 2020). Specifically, previous empirical studies which addressed CI acquisition (CIA) and CI utilization (CIU) in the hotel sector, especially in the Malaysian hotel context and tourism are still very scarce (Yap et al., 2014; Yap et al., 2018; Salguero et al., 2019; Köseoglu et al., 2020). Therefore, the use of firm performance (financial and nonfinancial performance) to evaluate the impact of CIA and CIU in the hotel sector is crucial (Yap et al., 2014; Yan-li \& He-feng, 2015; Köseoglu et al., 2016; Salguero et al., 2019; Köseoglu et al., 2020). Furthermore, these authors recommended that future studies should investigate CI dimensions in a variety of industries particularly the hotel industry. Thus, this study is one of the first to assess the influence of CIA and CIU on Malaysian hotels' financial and non-financial performance. Therefore, this study examines the following research questions:

$R Q 1$ : What is the nature of CI practice in Malaysian hotels?

$R Q 2$ : What is the rank of importance of CIA types and sources to marketing managers in Malaysian hotels?

RQ3: Do the CIA and CIU have an impact on financial and non-financial performance in Malaysian hotels? 


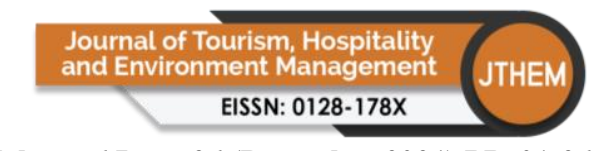

Volume 6 Issue 26 (December 2021) PP. 01-26

\section{Literature Review}

DOI 10/35631/JTHEM.626001

\section{Competitive Intelligence Acquisition and Utilization (CIA and CIU)}

The notion of CI has core military science underpinnings and a long and illustrious history stretching back more than 5,000 years (Tao \& Prescott, 2000; Oraee et al., 2020). As part of marketing strategy, the concept of intelligence has long been offered as a means of enhancing both the planning process and the competitiveness of businesses (Ashrafi \& Ravasan, 2018; Salguero et al., 2019). Additionally, the CI practice appears to have grown significantly in scope and is now regarded as one of the fastest-growing fields in the business domain, owing to CI's involvement with a variety of disciplines with varying theoretical foundations, such as management, economics, computer science, and information science, to name a few (Oraee et al., 2020). Additionally, professional organisations and scientific societies are involved in this field (Søilen, 2017; Oraee et al., 2020). CI is recognised as a critical strategic practice for organisations (Maritz \& du Toit, 2018; Oraee et al., 2020), which can be used to assist the hotel industry in evaluating competition, gaining advantages and coping with disadvantages and crises, seizing opportunities, and enabling hotel managers to make informed decisions about future events (Yan-Li \& He-feng, 2016; Maritz \& du Toit, 2018; Salguero et al., 2019; Köseoglu et al., 2020). Despite this, Köseoglu et al. (2019) and Oraee et al. (2020) identified a significant research gap regarding CI practise in emerging economies, emphasising the lack of knowledge regarding how CIA is conducted in these markets, where the institutional framework is significantly different than in developed economies. Generally, no precise and widely recognised definition of $\mathrm{CI}$ is provided; however, the literature contains numerous definitions of CI (Pellissier \& Nenzhelele, 2013; Oraee et al., 2020). Breakspear (2013) defines CI as a combination of two concepts: competition and intelligence. The former refers to a contest between two or more organisations, groups, or corporations. The latter refers to a corporate competency that integrates foresight and insights with the objective of identifying impending change, which may be favourable and represent opportunities, or negative and represent risks (Breakspear, 2013). Additionally, Yin (2018) and Oraee et al. characterise CI as a process or a product (2020). Competitive intelligence (CI) is defined by the Society of Competitive Intelligence Professionals (SCIP) as a continuous process that includes legal and ethical methods for gathering information, analysing it, and controlling its dissemination so that decision-makers can make informed decisions about marketing, research and development, and investing tactics, as well as long-term business strategies (SCIP, 2009). Meanwhile, CI is defined as the acquisition of information about the current and future behaviour of customers, competitors, and suppliers, as well as information on the government, market, and general business environment (Yin, 2018). As a result, the notion of CI was applied as an acquisition of CI in this study.

Competitive Intelligence Acquisition (CIA)Competitive Intelligence Acquisition (CIA) refers to the diversity of methods and sources utilised to gather information about an organization's internal and external environment, as well as the importance and frequency with which these methods and sources are used (Yap et al., 2014; Yap et al., 2018; Asghari et al., 2020; Madureira et al., 2021). CIA is the process of acquiring information about rivals, customers, suppliers, technology, the economy, and so on, and, ideally, integrating that information in short- and long-term strategic planning to stay one step ahead of the competition (Teo \& Choo, 2001; Yap et al., 2018; Asghari et al., 2020; Oraee et al., 2020). As well CIA refers to information that can be used to improve a company's competitive position in the external business environment. According to Teo and Choo (2001) CIA isn't the same as industrial 


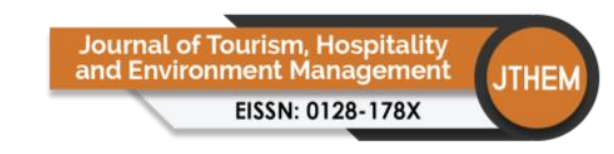

Volume 6 Issue 26 (December 2021) PP. 01-26 DOI 10/35631/JTHEM.626001

espionage. 90 percent of all information a firm needs to make vital decisions and understand its market and competitors is already available or can be methodically developed from public data, according to one of CI's key maxims (Teo \& Choo, 2001; Yap et al., 2018; Asghari et al., 2020; Oraee et al., 2020). In general, the CIA reflects the trends and interests of CI users. For example, some businesses use the CIA to monitor competitors, suppliers, customers, and technology, while others use it to monitor the economic and political conditions of the countries in which they invest in order to formulate plans and strategies based on the intelligence information produced by the CI unit. Additionally, the CIA denotes the type of information sources from which businesses get information via its CI unit. However, there is no agreement on which type and sources of CIA (Yap et al., 2014; Yap et al., 2018; Asghari et al., 2020). Given the lack of agreement on CIA sources in earlier studies, this highlights the necessity for additional research on the CIA.

Information acquisition occurs during the collection phase of the CIP, when information is obtained from a variety of sources (primary, secondary, internal, and external) for examination and assessment (Muller, 2004; Asghari et al., 2020). Employees, for example, are an internal source of information collection, whereas external sources are those outside the organisation such as customers and suppliers (Asghari et al., 2020; Lutz \& Bodendorf, 2020). Human sources, according to Lutz and Bodendorf (2020), provide more original and timely information. Muller (2004), on the other hand, stated that the published works primarily data is essential for analysis and cross-checking the given data by human sources. Additionally, Lutz and Bodendorf (2020) and Asghari et al. (2020) suggested that the critical success factor for a CIA practice is focusing on the essential information and knowing where and how to collect it. Environmental scanning is one of the ways of acquisition (Muller, 2004). The CIA operates in three stages: information gathering, classification, and storage (files, computer systems, library, etc.) (Yin, 2018; Collovini et al., 2020). Moreover, Rouach and Santi (2001) and Köseoglu et al. (2020) defined three distinct forms of information and its sources: open information sources (white data), private domain information sources (grey data), and unlawfully obtained information (black information). According to Muller (2004), information collection must be handled in accordance with CI's ethical and legal norms. In this regard, Marin and Poulter (2004) performed a poll of CIA practitioners and compiled a list of the ten most often used sources of CI, ranked from most to least frequently used. There is 94 percent of news providers, 93 percent of corporate websites, 90 percent of trade publications, 83 percent of competitor annual reports, 82 percent of employees (internal and competitor), 60 percent of trade shows, 60 percent of clients, 56 percent of senior management, and 42 percent of current awareness services, and 40 percent of suppliers. They said that the percentage shows the proportion of respondents who stated that they use the source on a regular basis for intelligence gathering. According to other researchers, the CIA's primary and public domain sources include archival materials, an online competitive database, published works, and onthe-record interviews with industry experts or corporate officials (Salguero et al., 2017; Collovini et al., 2020; Asghari et al., 2020). These sources enable the collection of data from a variety of corporate operations and resource deployments, such as marketing expenditures and capital investments in equipment and plant. In addition, previous studies in the Malaysian context identified consumers, competitors, suppliers, technology, newspapers and periodicals, Internet and extranets, global organisational, Web 2.0, economic, socio-cultural, and human resources, and regulators as public sources of information gathering (Yap et al., 2012; Yap et al., 2013; Yap et al., 2014; Yap et al., 2018). These sources are critical for gathering the information needed to assist decision-makers in marketing strategies and improve firm 


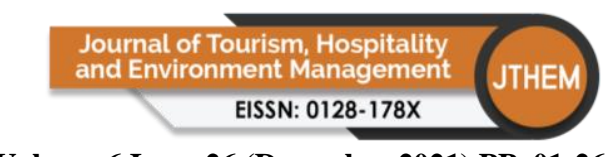

Volume 6 Issue 26 (December 2021) PP. 01-26 DOI 10/35631/JTHEM.626001

performance. Despite the growing importance of the CIA, particularly in the era of big data, very few studies have been conducted on its impact on the financial and non-financial performance of businesses, particularly in the Malaysian tourism and hotel sectors (Yap et al., 2014; Yap et al., 2018). This bolsters the study's argument about the criticality of understanding the hierarchy of CIA types and sources according to their importance to Malaysian hotel marketing managers, as well as the impact of CIA and CIU on financial and non-financial performance in Malaysian hotels, as this is one of the first studies to address such a growing research gap in a developing country like Malaysia.

\section{Hotel's Performance}

The performance of a hotel is concerned with the end result of hotel process activities (Wu \& Lu, 2012; Mohammed et al., 2017; Cheangtawee et al., 2020). Due to the dynamic and sophisticated nature of today's business world, performance assessment has become one of the most critical factors for enterprises (Mohammed et al., 2017; Wamba et al., 2019; Falahat et al., 2020). Thus, numerous scholars and researchers have recently displayed a surprising level of interest in the topic of performance assessment and management (Yap et al., 2018; Wamba et al., 2019; Falahat et al., 2020; Vugec et al., 2020). Thus, analysing performance using a comprehensive metric that encompasses all facets of a business's operations is crucial for supporting an organisation in effectively managing its resources and achieving its objectives (Wu \& Lu, 2012; Mohammed et al., 2017; Cheangtawee et al., 2020). This scale is used to assess both financial and non-financial performance (Kaplan \& Norton, 1992). Furthermore, Wu and Lu (2012), Mohammed et al. (2017), and Cheangtawee et al. (2020) all used financial and non-financial performance measures to evaluate hotel performance, and they found that this comprehensive metric is important to measure the overall performance of hotels. This metric takes four dimensions of corporate performance into account: financial, customer, internal processes, and learning and growth (Mohammed et al., 2017). According to Kaplan and Norton (1992), integrating these four perspectives enables managers to gain a better understanding of cross-functional interactions within their organisations, resulting in improved problem solving and decision making. According to Tej Adidam et al. (2012) and Yap et al. (2018), financial measures alone cannot capture the full extent of CI influence, and thus the total performance view should be used to evaluate CI outcomes. As a result, examining the impact of CIA and CIU on hotel performance (financial and non-financial performance) is conclusive because it is a useful metric for evaluating the hotel's overall operational performance (Tej Adidam et al., 2012; Yap et al., 2018). Finally, by combining financial and non-financial performance metrics, firms can gain a holistic view of their operations. As a result, the four performance measurement elements (customer, financial, internal process, and learning and growth) are used in this study to reflect and measure hotel performance.

\section{Hypotheses Development}

\section{CIA, CIU, and Hotels' Performance}

CI functions as a strategic tool for identifying opportunities and potential threats (du Toit, 2013; Hendar et al., 2020). Additionally, CI is a multidimensional construct that encompasses three dimensions: Competitive Intelligence Processes (CIP), Competitive Intelligence Context (CIC), and Competitive Intelligence Acquisition (CIA) (Saayman et al., 2008; Seyyed-Amiri et al., 2017; Yap et al., 2018). Additionally, the CI literature noted that the essence of CI is its capacity to enhance decision making and to assist decision makers in making informed decisions, which can result in competitive advantage and improved firm performance 


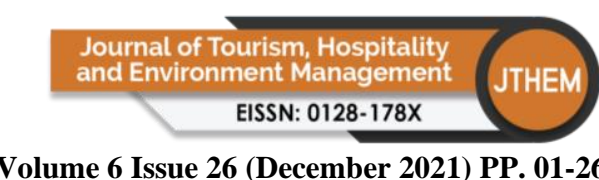

Volume 6 Issue 26 (December 2021) PP. 01-26

DOI 10/35631/JTHEM.626001

(Mohamad et al., 2018; Markovich et al., 2019; Salguero et al., 2019; Lutz \& Bodendorf, 2020; Oraee et al., 2020). In the age of big data, CIA is critical for organisations to compete in a fiercely competitive market by getting the high-quality information necessary for competitive advantage Yap et al., 2014; Yan-Li \& He-feng, 2016; Salguero et al., 2017; Yap et al., 2018; Yin, 2018; Asghari et al., 2020; Collovini et al., 2020). Management research has established the critical importance of information in buseniss activity (Teo \& Choo, 2001; Asghari et al., 2020). Indeed, gathering information is regarded as the first step toward conducting a CI practise and reaping the benefits of the knowledge (Shi et al., 2009; Gheysari, 2015). Clearly, the design and operation of CIA have an effect on the overall efficiency and practicality of CI practise (Salguero et al., 2017; Collovini et al., 2020; Asghari et al., 2020; Oraee et al., 2020). CIA, as a component of the CI practise, is a critical strategic activity that assists organisations in assessing emerging trends in their business environments, major and prospective risks, and Competitiveness (Salguero et al., 2017; Collovini et al., 2020; Asghari et al., 2020). As a result, CI analysts tend to secure information regarding the firm's business plans, strategic capabilities, intellectual properties, technological processes, product formulations and threats posed by their potential competitors (Salguero et al., 2017; Collovini et al., 2020; Asghari et al., 2020). Indeed, having accurate knowledge about the environment and competitors boosts a firm's effectiveness and contributes to its competitiveness, improving performance (Gheysari, 2015; Ashrafi \& Ravasan, 2018; Yin, 2018; Asghari et al., 2020).In addition, the majer challenge for most hotel managers is making rational decisions in an atmosphere marked by environmental uncertainty, as well as dealing with customers of various ethnicities, cultures, and religions (Yap et al., 2014; Köseoglu et al., 2020; Mariani et al., 2020). Furthermore, certain elements of the hotel marketing environment, such as severe rivalry, seasonal variations, and imitation barriers, place a greater burden on hotel managers than on others (Köseoglu et al., 2020). As a result, CIA practice and frequance to use it obtaining more information on many areas of the hotel market may enhance market share (Yan-li \& He-feng, 2015; Köseoglu et al., 2019; Salguero et al., 2019; Ahn \& Kwon, 2020; Köseoglu et al., 2020). Furthermore, Yap et al. (2014) discovered that Malaysian hotels continue to underutilize Web 2.0 tools for market intelligence acquisition (MIA). Additionally, they discovered a favorable correlation between MI acquisition, environmental instability, and hotel performance in Malaysia. Additionally, Yap and Rashid (2011) discovered that the frequency with which personal and external sources are used in strategic decision making is significantly higher than the frequency with which impersonal and internal sources are used, and they discovered a positive correlation between CIA practice and firms' performance in Malaysia. Therefore, we proposed the following hypotheses:

H1: The CIA influences hotels' performance in Malaysia.

$\mathrm{H} 2$ : The CIU influences hotels' performance in Malaysia.

According to the theoretical framework and prior hypotheses, the conceptual framework will be depicted as in Fig.1. 


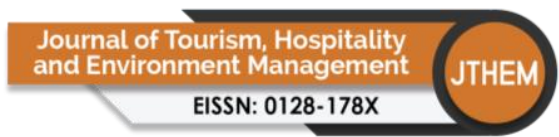

Volume 6 Issue 26 (December 2021) PP. 01-26

DOI 10/35631/JTHEM.626001

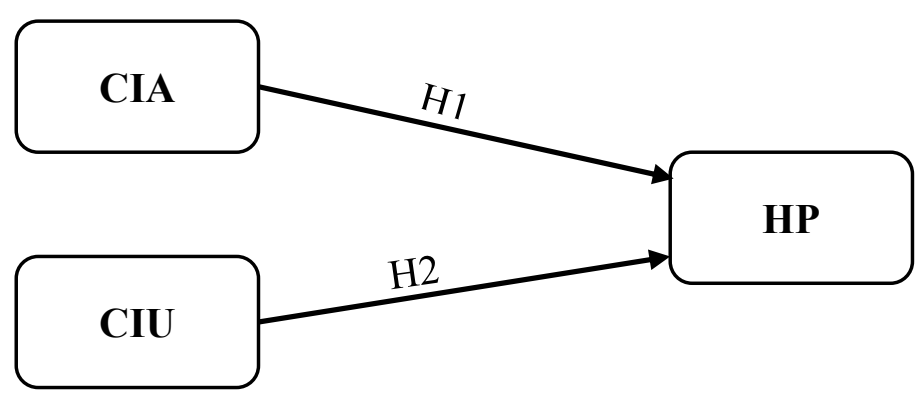

Figure1: The conceptual framework

\section{Methodology}

The primary objectives of this research are to define the nature of CI practise in Malaysian hotels, to illustrate the relative importance of various CIA types and sources to marketing managers in Malaysian hotels, and to investigate the impact of CIA and CIU on the financial and non-financial performance of Malaysian hotels. To accomplish these objectives, we used a quantitative approach to collect data from marketing managers at Malaysian hotels. There is empirical evidence from previous studies in which researchers used hotel marketing managers as primary respondents, for example, Yap et al. (2014), Köseoglu et al. (2016) and Köseoglu et al. (2019). Additionally, Yap et al. (2014), Köseoglu et al. (2019) and Markovich et al. (2019) noted that the CI unit is located within marketing management. As a result, it is expected that marketing managers will be correct in their responses to practically all questions. The study population consisted of Malaysian hotels with three to five-star ratings, which numbered 535 in December 2018, according to the Malaysian Association of Hotels (MAH, 2018). Yap et al. (2014) and Köseoglu et al. (2016) suggested that these sorts of hotels are suited for exploring CI because their management organisation, information handling, and institutionalisation are superior to those of one-star and two-star hotels. Due to the study population's modest size, Zikmund (2003) and Zikmund et al. (2013) urged researchers to analyse the complete population rather than picking a sample size. As a result, we conducted a survey of the overall population, which includes 535 three- to five-star hotels according to the MAH membership database. Due of the dispersed nature of Malaysian hotels, data was acquired via a questionnaire over a four-month period from November 2019 to February 2020. After removing the 30 hotels from the pilot survey, questionnaires were delivered via email to 505 hotel marketing managers. Due to the low incidence of email survey recovery, researchers visited hotels in Northern Malaysia (Pulau Pinang, Kedah, and Perlis), as well as the majority of hotels in Kuala Lumpur, Selangor, and Malacca, recovering a total of 192 questionnaires. After removing damaged questionnaires and outlier data, the final examination of the questionnaires received revealed 184 (36.44 percent) that were suitable for data analysis. Male respondents made up 45.1 percent of the total, while female respondents made up 54.9 percent. 44.6 percent of respondents were between the ages of 36 and 45. All respondents held a managerial position, with the marketing manager position accounting for the majority $(91.3$ percent), followed by the sales manager position (7.6 percent). As a result, all respondents were deemed qualified to provide responses regarding the hotel's performance and CIA practises. They were also aware of CI practises, as the majority of respondents (68\%) had worked in this hotel for four to nine years, while the majority (67.4 percent) had ten years or more of experience working in the hotel business. 31.5 percent of hotels were rated as "three-star," 40.2 percent as "four-star," and the remainder as "five-star." On the other side, the bulk of hotels were categorised as city hotels (78.8 percent). $75 \%$ of hotels have been established for at least 


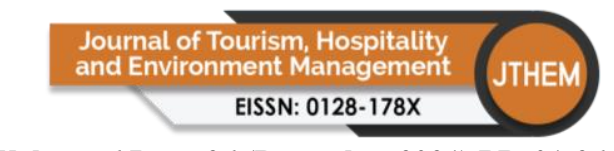

Volume 6 Issue 26 (December 2021) PP. 01-26

DOI 10/35631/JTHEM.626001

ten years, indicating that they are mature establishments. The majority of these hotels possessed in excess of 300 rooms. Additionally, Selangor had the highest response rate, at 26.6 percent.

\section{Measures}

The CIA and CIU measurement in this study was based on fifty items separated into four dimensions, two dimensions of which represented CIA (as a second-order) and two dimensions of which represented CIU, (as a second-order), depending on the perceived importance for acquiring CIA (by type and source) and the CI-frequency of utilization (by type and source) were drawn from Daft et al. (1988), which were refined by Yap et al. (2014) and Yap et al. (2018). Additionally, the perceived value of each CIA type and source was quantified using a "five-point scale (ranging from 1 for insignificant to 5 for extremely significant)". Whereas the CIU-frequency was quantified by kind and source on a "five-point scale (from 1=extremely low to 5=extremely high)". Furthermore, hotel's performance (HP) has been measured by the four elements of financial and non-financial performance (customer (HP-CP) has 4 items, financial (HP-FP) has 5 items, internal process (HP-IPP) has 4 items, and learning and growth (HP-LGP) has 4 items) were drawn from Kaplan and Norton (1992), which were refined by Mohammed et al. (2017), where it included 17 items, with the four dimensions of HP were assessed using a "5-point Likert scale, with 1 indicating "strongly disagree" and 5 indicating "strongly agree" for the statements proposed". After that, respondents were asked to give their opinions on CIA, CIU and HP in their hotels over the previous three years.

\section{Results}

Two statistical packages were used to examine the results of this study and to accomplish its objectives: the statistical package for social sciences "SPSS" version 26 and "structural equation modelling for partial least squares (SEM-PLS) version 3.3.3." The first package was used to determine the level of CI practice in Malaysian hotels, and the rank of importance of CIA types and sources to marketing managers in Malaysian hotels. While we used SEM-PLS to evaluate the measurement and structural models, for report key findings on the "measurement model" and "structural model," which include constructing, validating discriminant and convergent models, analysing reliability, and determining the model's predictive significance. PLS route modelling has increased its use in a number of study domains, including strategic management, marketing, information systems, social psychology, and management science (Hair et al., 2019). According to Hair et al. (2019), PLS-SEM is a viable and robust method for a variety of circumstances encountered in social science research.

\section{The Nature of CI practice in Malaysian hotels}

As illustrated in Table 1, descriptive statistics in the form of frequencies and percentages were calculated in connection to the nature of CI use in Malaysian hotels. 51.1 percent of Malaysian hotels employ CI on an informal basis, while 48.9 percent use it on a formal basis. Meanwhile, 74.5 percent of hotels indicated that the CI is housed inside Marketing/Market research Management, while $13.6 \%$ indicated that the CI is housed within a distinct department. Additionally, 58.7 percent of hotels implemented CI in less than five years, while 37.5 percent implemented CI in five to ten years. Additionally, $56 \%$ of hotels have between one and five staff engaged in CI operations, while 21.7 percent have between six and ten employees engaged in CIP activities. 
Table 1: Descriptive Statistics of The Nature of CI practice in Malaysian Hotels $(\mathrm{N}=184)$

\begin{tabular}{cccc}
\hline Variable & Description & F & \% \\
\hline \multirow{2}{*}{ Using CI } & Yes & 184 & 100 \\
Type of & No & 0 & 0.0 \\
using CI & Formal & 90 & 48.9 \\
& Informal & 94 & 51.1 \\
& Market/Marketing research & 137 & 74.5 \\
CIP unit & Corporate planning & 8 & 4.3 \\
Location & The Finance & 5 & 2.7 \\
& Research \& development & 5 & 2.7 \\
& Information Technology & 2 & 1.1 \\
& A separate department & 25 & 13.6 \\
Years of CI & Others & 2 & 1.1 \\
unit & lesser than-5 years & 108 & 58.7 \\
established & 5-10-Years & 69 & 37.5 \\
& 11-15-Years & 2 & 1.1 \\
Number of & 16-Years and More & 5 & 2.7 \\
employees & 1-5-Employee & 103 & 56.0 \\
involved in & 6-10-Employee & 40 & 21.7 \\
CI activities & 11-15-Employee & 21 & 11.4 \\
& more than 15-employee & 2 & 1.1 \\
& No dedicated set of employees & 18 & 9.8 \\
\hline
\end{tabular}

In order to measure the relative importance of various CIA types and sources to marketing managers in Malaysian hotels, descriptive statistics were calculated that include mean, deviations' standards, the relative importance index (RII), as well the level of the relative importance index (RII-Level). As explained above, structures were measured in the current study using the "5-point Likert scale". So, we used three classes depending on Noor and Kumar (2014), to show the categories of arithmetic mean, namely: the low values which are less than 2.33 ("4/3 + lowest-value (1)"), the high values which are higher than 3.67 (the highest-value "(5) - 4/3)" and the moderate values which are located among high and low values. Furthermore, according to Johnson and LeBreton (2004), the Relative Importance Index (RII) is important for evaluating and ranking the factors identified in the study that use the Likert scale. Where in the case of the five-point Likert scale, the following categories are used to arrange the relative importance of each factor: $0.80 \leq$ RII $\leq 1$ considered High $(\mathrm{H}), 0.60 \leq$ RII $\leq 0.80$ considered from Medium to High $(\mathrm{M}-\mathrm{H}), 0.40 \leq \mathrm{RII} \leq 0.60$ considered Medium $(\mathrm{M})$, $0.40 \leq \mathrm{RII} \leq 0.20$ considered from Low to Medium (L-M), and $0 \leq \mathrm{RII} \leq 0.20$ considered Low (L). Table 2, showed the mean and standard deviations, and the Relative Importance Index (RII), and the level of RII for the type and source of CIA to illustrate the relative importance of various CIA types and sources to marketing managers in Malaysian hotels.

Furthermore, Tables 2 and 3, and Figures 2 and 3 illustrate the values of mean, standard deviation values, RII, RII-levels and ranks for the types and sources of CIA in Malaysian hotels. Where the overall mean for all types of CIA ranged between, 3.21 to 4.75 , which indicated that all types of CIA get moderate to the high level of mean values, as well the total mean value of CIA's types had a high level of mean with 3.89 value, as well the overall standard deviation for all items ranged between $(0.57-1.00)$, as displayed in table 2 , which indicates 


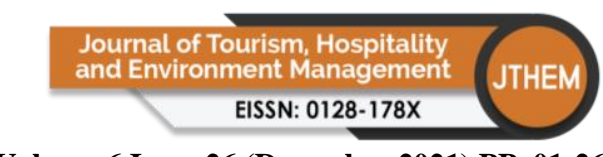

Volume 6 Issue 26 (December 2021) PP. 01-26 DOI 10/35631/JTHEM.626001

that there is no significant variation in the interests of marketing managers in Malaysian hotels in terms of the types of CIA. With regard to ranking the types of CIA according to their relative importance to the marketing managers of Malaysian hotels, competitors and customers obtained a high level of importance with RII-values of (0.95 and 0.94) respectively, while the rest of the types obtained the medium to high levels importance values. Therefore, the five most important types of CIA to Malaysian hotel marketing managers can be arranged as follows: (1) competitors, (2) customers, (3) human resources, (4) socio-cultural, and (5) Global, the types are arranged in descending order from most important to least important. See Table 2, and Figure 2.

In addition, the overall mean for all sources of CIA ranged between, 3.21 to 4.55, which indicated that all sources of CIA get moderate to high level of mean values, as well the total mean value of CIA's sources had a high level of mean with 3.91 value, as well the overall standard deviation for all items ranged between ( 0.65 to 0.93 ), as displayed in table 2 , which indicates that there is no significant variation in the interests of marketing managers in Malaysian hotels in terms of the CIA's sources. With regard to ranking the sources of CIA according to their relative importance to the marketing managers of Malaysian hotels, the internet and extranets, customers, electronic information services/intranets, business associates, newspapers and periodicals, and industry trade associations obtained a high level of importance with RII-values of $(0.91,0.88,0.87,0.84,0.83$ and 0.83$)$ respectively, while the rest of the sources obtained the medium to high levels importance values. Therefore, the five most important sources of CIA to Malaysian hotel marketing managers can be arranged as follows: (1) the internet and extranets, (2) customers, (3) electronic information services/intranets, (4) business associates, and (5) newspapers and periodicals, and industry trade associations, the sources are arranged in descending order from most important to least important. See Table 3, and Figure 3. This reflects the interest of marketing managers in Malaysian hotels on the importance of types and sources of CIA and its impact of hotel's performance.

Table 2: Means, Std. Deviation, RII. RII-Level and Ranking of the CIA's Types in Malaysian hotels ( $N=184)$

\begin{tabular}{ccccccc}
\hline Type of CIA & Code & Mean & $\begin{array}{c}\text { Std. } \\
\text { Deviation }\end{array}$ & RII & $\begin{array}{c}\text { RII- } \\
\text { Level }\end{array}$ & Rank \\
\hline Customer & CIAT1 & 4.71 & 0.62 & 0.94 & $\mathrm{H}$ & $\mathbf{( 2 )}$ \\
Competitor & CIAT2 & 4.75 & 0.57 & 0.95 & $\mathrm{H}$ & $\mathbf{( 1 )}$ \\
Supplier & CIAT3 & 3.51 & 0.75 & 0.70 & M-H & $(7)$ \\
Regulatory & CIAT4 & 3.21 & 1.00 & 0.64 & M-H & $(8)$ \\
Economic & CIAT5 & 3.59 & 0.65 & 0.72 & M-H & $(6)$ \\
Socio-cultural & CIAT6 & 3.91 & 0.73 & 0.78 & M-H & $(\mathbf{4})$ \\
Human resources & CIAT7 & 3.98 & 0.70 & 0.80 & M-H & $(\mathbf{3})$ \\
Global & CIAT8 & 3.84 & 0.75 & 0.77 & M-H & $\mathbf{( 5 )}$ \\
Organisational & CIAT9 & 3.59 & 0.80 & 0.72 & M-H & $(6)$ \\
Total & CIAT & $\mathbf{3 . 8 9}$ & $\mathbf{0 . 4 5}$ & $\mathbf{0 . 7 8}$ & M-H & $\mathbf{- -}$ \\
\hline
\end{tabular}




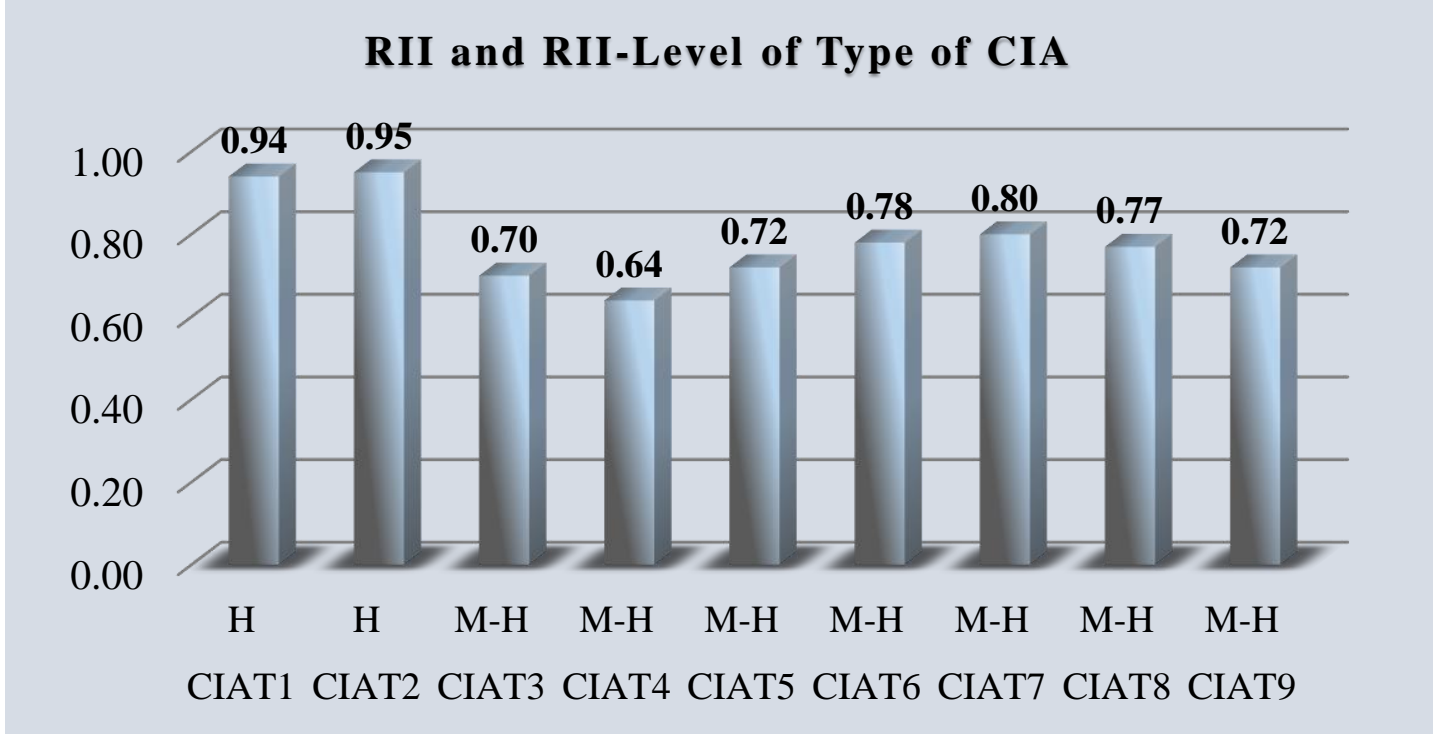

Figure 2: RII and RII-Level of the CIA's Types

Table 3: Means, Std. Deviation, RII. RII-Level and Ranking of the CIA's Sources in Malaysian hotels $(\mathrm{N}=184)$

\begin{tabular}{ccccccc}
\hline Sources of CIA & Code & Mean & $\begin{array}{c}\text { Std. } \\
\text { Deviation }\end{array}$ & RII & $\begin{array}{c}\text { RII- } \\
\text { Level }\end{array}$ & Rank \\
\hline Customers & CIAS1 & 4.38 & 0.72 & 0.88 & $\mathrm{H}$ & $\mathbf{( 2 )}$ \\
Competitors & CIAS2 & 3.68 & 0.83 & 0.74 & $\mathrm{M}-\mathrm{H}$ & $(7)$ \\
Business associates & CIAS3 & 4.19 & 0.65 & 0.84 & $\mathrm{H}$ & $\mathbf{( 4 )}$ \\
Government officials & CIAS4 & 4.02 & 0.93 & 0.80 & $\mathrm{M}-\mathrm{H}$ & $(6)$ \\
Newspapers, periodicals & CIAS5 & 4.14 & 0.84 & 0.83 & $\mathrm{H}$ & $\mathbf{( 5 )}$ \\
Government publications & CIAS6 & 4.02 & 0.92 & 0.80 & $\mathrm{M}-\mathrm{H}$ & $(6)$ \\
Industry, trade associations & CIAS7 & 4.16 & 0.78 & 0.83 & $\mathrm{H}$ & $\mathbf{( 5 )}$ \\
The Internet and extranets & CIAS8 & 4.55 & 0.68 & 0.91 & $\mathrm{H}$ & $\mathbf{( 1 )}$ \\
Conference, seminar, trade & CIAS9 & 3.69 & 0.78 & 0.74 & $\mathrm{M}-\mathrm{H}$ & $(7)$ \\
show, business trip & & & & & & \\
Superior, board members & CIAS10 & 3.72 & 0.71 & 0.74 & $\mathrm{M}-\mathrm{H}$ & $(7)$ \\
Subordinate managers & CIAS11 & 3.64 & 0.66 & 0.73 & $\mathrm{M}-\mathrm{H}$ & $(8)$ \\
Subordinate staff & CIAS12 & 3.62 & 0.65 & 0.72 & $\mathrm{M}-\mathrm{H}$ & $(9)$ \\
Internal memo, circulars & CIAS13 & 3.59 & 0.68 & 0.72 & $\mathrm{M}-\mathrm{H}$ & $(9)$ \\
Internal reports & CIAS14 & 3.70 & 0.70 & 0.74 & $\mathrm{M}-\mathrm{H}$ & $(7)$ \\
Company library & CIAS15 & 3.21 & 0.75 & 0.64 & $\mathrm{M}-\mathrm{H}$ & $(10)$ \\
Electronic information & CIAS16 & 4.33 & 0.79 & 0.87 & $\mathrm{H}$ & $\mathbf{( 3 )}$ \\
services/intranets & & $\mathbf{3 . 9 1}$ & $\mathbf{0 . 5 1}$ & $\mathbf{0 . 7 8}$ & M-H & $\mathbf{- -}$ \\
Total & & & & & &
\end{tabular}




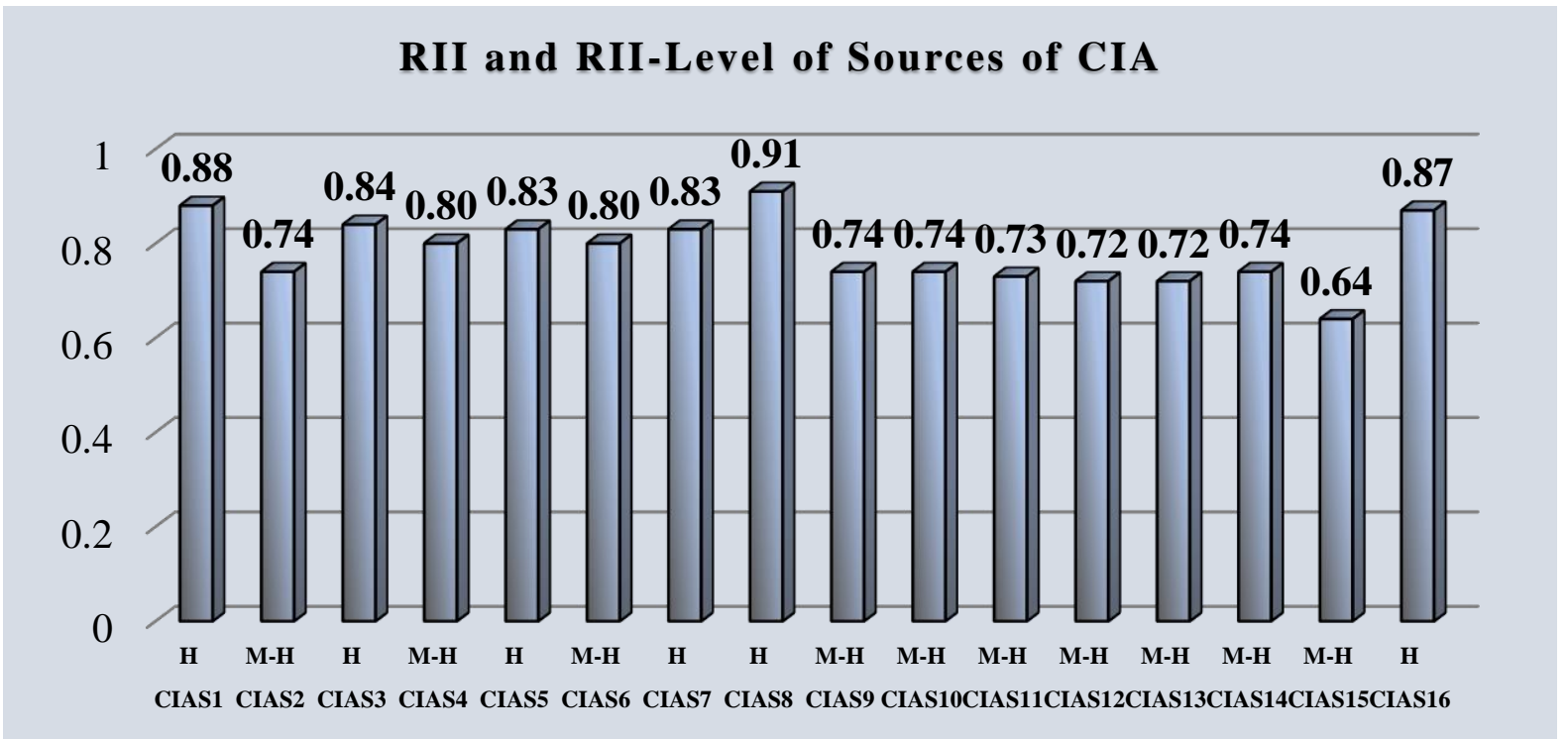

Figure 3: RII and RII-Level of the CIA's Sources

\section{The Resulting of The Measurement Model}

Hair et al. (2019) guidelines were utilised to evaluate the measurement model, focusing on the construct, convergent, and discriminant validity. When a test is designed, construct validity refers to the use of the results acquired via the application of the measure and relevant theories (Sekaran \& Bougie, 2016). This concept can be realised by examining the item's factor loading in the content validity of the measurement model (Chin, 2010; Hair et al., 2014). In this circumstance, all items should be much more loading on their hypothesised factor than on other factors (Chin, 2010). As a result, if certain items have a load that exceeds their respective build, they are destroyed (Hair et al., 2014). The current study used a threshold value of 0.70 as a highly significant value for factor loadings. Taking into account the effects of item removal on the composite's reliability and content validity, as proposed by Hair et al. (2014) and Hair et al. (2017). As a result, several items were used despite having loadings less than 0.70 but greater than 0.40 , because eliminating them would degrade the quality of the content, as recommended by Hair et al., (2014) and Hair et al. (2017). Table 4, shows that the loading of the item was greater than the loading of the other items at all variables' items. As a result, this conclusion supports the measurement model's content validity.

Table 4: Loadings and Cross-Loadings

\begin{tabular}{|c|c|c|c|c|c|c|c|c|}
\hline Item & CIA-T & CIA-S & CIU-T & CIU-S & HP-CP & HP-FP & HP-IPP & $\begin{array}{c}\text { HP- } \\
\text { LGP }\end{array}$ \\
\hline CIAT1 & $\mathbf{0 . 4 6 3}$ & 0.291 & 0.324 & 0.158 & 0.230 & 0.139 & 0.296 & 0.224 \\
\hline CIAT5 & $\mathbf{0 . 7 3 0}$ & 0.526 & 0.549 & 0.309 & 0.116 & 0.199 & 0.044 & 0.037 \\
\hline CIAT6 & $\mathbf{0 . 7 1 9}$ & 0.393 & 0.409 & 0.045 & 0.167 & 0.231 & 0.049 & 0.053 \\
\hline CIAT7 & $\mathbf{0 . 7 8 8}$ & 0.434 & 0.503 & 0.215 & 0.407 & 0.390 & 0.407 & 0.251 \\
\hline CIAT8 & $\mathbf{0 . 7 7 0}$ & 0.663 & 0.643 & 0.552 & 0.385 & 0.404 & 0.385 & 0.354 \\
\hline CIAT9 & $\mathbf{0 . 7 5 4}$ & 0.571 & 0.524 & 0.371 & 0.270 & 0.256 & 0.176 & 0.153 \\
\hline CIAT10 & $\mathbf{0 . 8 5 6}$ & 0.591 & 0.644 & 0.424 & 0.242 & 0.329 & 0.282 & 0.250 \\
\hline CIAS3 & 0.486 & $\mathbf{0 . 7 1 7}$ & 0.483 & 0.435 & 0.481 & 0.477 & 0.468 & 0.361 \\
\hline CIAS4 & 0.525 & $\mathbf{0 . 8 0 7}$ & 0.682 & 0.612 & 0.579 & 0.533 & 0.525 & 0.515 \\
\hline
\end{tabular}


Volume 6 Issue 26 (December 2021) PP. 01-26 DOI 10/35631/JTHEM.626001

\begin{tabular}{|c|c|c|c|c|c|c|c|c|}
\hline CIAS5 & 0.360 & 0.695 & 0.563 & 0.672 & 0.630 & 0.510 & 0.650 & 0.651 \\
\hline CIAS6 & 0.427 & 0.780 & 0.622 & 0.727 & 0.628 & 0.547 & 0.601 & 0.585 \\
\hline CIAS7 & 0.630 & 0.798 & 0.658 & 0.633 & 0.607 & 0.585 & 0.592 & 0.503 \\
\hline CIAS8 & 0.395 & 0.555 & 0.408 & 0.425 & 0.489 & 0.407 & 0.502 & 0.345 \\
\hline CIAS9 & 0.519 & 0.581 & 0.382 & 0.387 & 0.049 & 0.207 & -0.037 & 0.082 \\
\hline CIAS10 & 0.591 & 0.803 & 0.475 & 0.561 & 0.279 & 0.467 & 0.172 & 0.195 \\
\hline CIAS11 & 0.621 & 0.811 & 0.590 & 0.551 & 0.306 & 0.456 & 0.193 & 0.197 \\
\hline CIAS12 & 0.594 & 0.823 & 0.563 & 0.558 & 0.320 & 0.371 & 0.190 & 0.200 \\
\hline CIAS13 & 0.536 & 0.803 & 0.526 & 0.579 & 0.320 & 0.338 & 0.211 & 0.192 \\
\hline CIAS14 & 0.548 & 0.739 & 0.494 & 0.510 & 0.215 & 0.260 & 0.149 & 0.155 \\
\hline CIAS15 & 0.356 & 0.593 & 0.395 & 0.334 & 0.106 & 0.211 & 0.024 & 0.186 \\
\hline CIAFT1 & 0.184 & 0.280 & 0.413 & 0.290 & 0.390 & 0.311 & 0.448 & 0.355 \\
\hline CIAFT3 & 0.387 & 0.517 & 0.601 & 0.533 & 0.274 & 0.278 & 0.350 & 0.460 \\
\hline CIAFT5 & 0.589 & 0.526 & 0.740 & 0.385 & 0.149 & 0.250 & 0.133 & 0.187 \\
\hline CIAFT6 & 0.615 & 0.515 & 0.781 & 0.310 & 0.337 & 0.343 & 0.253 & 0.275 \\
\hline CIAFT7 & 0.544 & 0.491 & 0.797 & 0.448 & 0.579 & 0.488 & 0.557 & 0.485 \\
\hline CIAFT8 & 0.625 & 0.636 & 0.854 & 0.695 & 0.460 & 0.435 & 0.505 & 0.484 \\
\hline CIAFT9 & 0.628 & 0.600 & 0.794 & 0.532 & 0.377 & 0.322 & 0.304 & 0.326 \\
\hline CIAFT10 & 0.609 & 0.648 & 0.893 & 0.640 & 0.401 & 0.407 & 0.418 & 0.484 \\
\hline CIAFS3 & 0.338 & 0.559 & 0.556 & 0.706 & 0.375 & 0.293 & 0.431 & 0.413 \\
\hline CIAFS4 & 0.354 & 0.654 & 0.653 & 0.804 & 0.582 & 0.460 & 0.557 & 0.521 \\
\hline CIAFS5 & 0.197 & 0.561 & 0.521 & 0.817 & 0.548 & 0.402 & 0.583 & 0.584 \\
\hline CIAFS6 & 0.259 & 0.611 & 0.589 & 0.853 & 0.603 & 0.469 & 0.595 & 0.569 \\
\hline CIAFS7 & 0.479 & 0.694 & 0.663 & 0.832 & 0.613 & 0.519 & 0.600 & 0.529 \\
\hline CIAFS8 & 0.287 & 0.410 & 0.407 & 0.564 & 0.448 & 0.283 & 0.462 & 0.283 \\
\hline CIAFS9 & 0.348 & 0.460 & 0.441 & 0.686 & 0.125 & 0.173 & 0.102 & 0.191 \\
\hline CIAFS10 & 0.348 & 0.518 & 0.437 & 0.767 & 0.238 & 0.321 & 0.170 & 0.151 \\
\hline CIAFS11 & 0.355 & 0.558 & 0.419 & 0.771 & 0.267 & 0.337 & 0.162 & 0.154 \\
\hline CIAFS12 & 0.326 & 0.589 & 0.448 & 0.808 & 0.321 & 0.282 & 0.210 & 0.221 \\
\hline CIAFS13 & 0.411 & 0.640 & 0.459 & 0.774 & 0.283 & 0.263 & 0.212 & 0.174 \\
\hline CIAFS14 & 0.404 & 0.605 & 0.481 & 0.776 & 0.245 & 0.192 & 0.160 & 0.097 \\
\hline CIAFS15 & 0.190 & 0.435 & 0.390 & 0.594 & 0.109 & 0.156 & 0.039 & 0.154 \\
\hline CIAFS16 & 0.269 & 0.440 & 0.525 & 0.782 & 0.498 & 0.313 & 0.589 & 0.532 \\
\hline HP_CP1 & 0.363 & 0.514 & 0.508 & 0.526 & 0.898 & 0.728 & 0.767 & 0.537 \\
\hline HP_CP2 & 0.309 & 0.447 & 0.448 & 0.444 & 0.930 & 0.645 & 0.791 & 0.603 \\
\hline HP_CP3 & 0.299 & 0.446 & 0.387 & 0.384 & 0.807 & 0.598 & 0.692 & 0.532 \\
\hline HP_CP4 & 0.274 & 0.442 & 0.397 & 0.433 & 0.859 & 0.584 & 0.711 & 0.597 \\
\hline HP_FP1 & 0.216 & 0.482 & 0.447 & 0.439 & 0.559 & 0.814 & 0.541 & 0.516 \\
\hline HP_FP2 & 0.189 & 0.377 & 0.285 & 0.307 & 0.624 & 0.791 & 0.642 & 0.459 \\
\hline HP_FP3 & 0.396 & 0.435 & 0.397 & 0.329 & 0.649 & 0.790 & 0.650 & 0.506 \\
\hline HP_FP4 & 0.480 & 0.574 & 0.472 & 0.385 & 0.606 & 0.899 & 0.651 & 0.540 \\
\hline
\end{tabular}


Volume 6 Issue 26 (December 2021) PP. 01-26 DOI 10/35631/JTHEM.626001

\begin{tabular}{|c|c|c|c|c|c|c|c|c|} 
HP_FP5 & 0.341 & 0.508 & 0.402 & 0.358 & 0.631 & $\mathbf{0 . 8 9 8}$ & 0.630 & 0.522 \\
\hline HP_IPP1 & 0.292 & 0.367 & 0.402 & 0.363 & 0.740 & 0.613 & $\mathbf{0 . 8 2 6}$ & 0.598 \\
\hline HP_IPP2 & 0.144 & 0.265 & 0.322 & 0.374 & 0.655 & 0.518 & $\mathbf{0 . 8 3 8}$ & 0.631 \\
\hline HP_IPP3 & 0.304 & 0.443 & 0.498 & 0.454 & 0.782 & 0.722 & $\mathbf{0 . 9 4 2}$ & 0.807 \\
\hline HP_IPP4 & 0.373 & 0.481 & 0.524 & 0.494 & 0.817 & 0.757 & $\mathbf{0 . 9 3 3}$ & 0.750 \\
\hline HP_LGP1 & 0.210 & 0.355 & 0.471 & 0.448 & 0.600 & 0.455 & 0.732 & $\mathbf{0 . 8 3 5}$ \\
\hline HP_LGP2 & 0.129 & 0.265 & 0.328 & 0.266 & 0.558 & 0.490 & 0.686 & $\mathbf{0 . 8 2 6}$ \\
\hline HP_LGP3 & 0.274 & 0.431 & 0.491 & 0.394 & 0.487 & 0.565 & 0.613 & $\mathbf{0 . 8 5 1}$ \\
\hline HP_LGP4 & 0.266 & 0.404 & 0.445 & 0.389 & 0.517 & 0.518 & 0.606 & $\mathbf{0 . 8 2 9}$ \\
\hline
\end{tabular}

The construct being measured can be estimated using factor loadings, composite reliability (CR), and the extracted average variance (AVE). The recommended loading is set at 0.70, however, items with the loading of items less than 0.70 but larger than 0.40 may be used, as removing them would damage the content's quality, provided, CR must be greater than 0.70 , and AVE should be greater than the generally accepted cut-off point of 0.50 , as advised by Hair et al. (2014) and Hair et al. (2017). Accordingly, there were after deleted nine items that had loading less than 0.40, are (CIAT2, CIAT3, CIAT4, CIAS1, CIAS2, CIAFT2, CIAFT4, CIAFS1, and CIAFS2). Using item loadings, the item loading for the hypothesized factor was found to be significantly higher than the other components (Chin, 2010). Furthermore, CR findings were higher than outcomes that were over 0.70. The AVE indicates that the latent variable was greater than 0.50 (Hair et al., 2019). The findings in Table 5 are higher than predicted levels, thereby validating the convergent validity of the measuring model.

Table 5: Loading Factor and Convergent Validity Findings

\begin{tabular}{|c|c|c|c|c|c|}
\hline Construct & $\begin{array}{c}\text { Second- } \\
\text { Order } \\
\text { Dimensions }\end{array}$ & $\begin{array}{l}\text { Measurement } \\
\text { Item }\end{array}$ & Loading & $\begin{array}{l}\text { Composite } \\
\text { Reliability } \\
\text { (CR) }\end{array}$ & $\begin{array}{c}\text { Average } \\
\text { Variance } \\
\text { Extracted } \\
\text { (AVE) }\end{array}$ \\
\hline \multirow{16}{*}{$\begin{array}{l}\text { Competitive } \\
\text { Intelligence } \\
\text { Acquisition } \\
\text { (CIA) }\end{array}$} & \multirow{7}{*}{$\begin{array}{l}\text { CIA's } \\
\text { Types }\end{array}$} & CIAT1 & 0.463 & \multirow{7}{*}{0.889} & \multirow{7}{*}{0.540} \\
\hline & & CIAT5 & 0.730 & & \\
\hline & & CIAT6 & 0.719 & & \\
\hline & & CIAT7 & 0.788 & & \\
\hline & & CIAT8 & 0.770 & & \\
\hline & & CIAT9 & 0.754 & & \\
\hline & & CIAT10 & 0.856 & & \\
\hline & \multirow{9}{*}{$\begin{array}{l}\text { CIA's } \\
\text { Sources }\end{array}$} & CIAS3 & 0.717 & \multirow{9}{*}{0.938} & \multirow{9}{*}{0.543} \\
\hline & & CIAS4 & 0.807 & & \\
\hline & & CIAS5 & 0.695 & & \\
\hline & & CIAS6 & 0.780 & & \\
\hline & & CIAS7 & 0.798 & & \\
\hline & & CIAS8 & 0.555 & & \\
\hline & & CIAS9 & 0.581 & & \\
\hline & & CIAS10 & 0.803 & & \\
\hline & & CIAS11 & 0.811 & & \\
\hline
\end{tabular}




\begin{tabular}{|c|c|c|c|c|c|}
\hline & & & & $\begin{array}{l}\text { nal of Tou } \\
\text { :nvironme }\end{array}$ & $\begin{array}{l}\text { spitality } \\
\text { gement } \\
-178 \mathrm{X}\end{array}$ \\
\hline & & & & $\begin{array}{r}\text { ssue } 26 \\
\text { DO } \\
\end{array}$ & $\begin{array}{l}\text { per 2021) } \\
31 / \text { JTHE }\end{array}$ \\
\hline & & CIAS12 & 0.823 & & \\
\hline & & CIAS13 & 0.803 & & \\
\hline & & CIAS14 & 0.739 & & \\
\hline & & CIAS15 & 0.593 & & \\
\hline & & CIAFT1 & 0.413 & & \\
\hline & & CIAFT3 & 0.601 & & \\
\hline & & CIAFT5 & 0.740 & & \\
\hline & CIU's & CIAFT6 & 0.781 & 0908 & 0560 \\
\hline & Types & CIAFT7 & 0.797 & 0.900 & 0.500 \\
\hline & & CIAFT8 & 0.854 & & \\
\hline & & CIAFT9 & 0.794 & & \\
\hline & & CIAFT10 & 0.893 & & \\
\hline & & CIAFS3 & 0.706 & & \\
\hline Competitive & & CIAFS4 & 0.804 & & \\
\hline Intelligence & & CIAFS5 & 0.817 & & \\
\hline Utilization & & CIAFS6 & 0.853 & & \\
\hline (CIU) & & CIAFS7 & 0.832 & & \\
\hline & & CIAFS8 & 0.564 & & \\
\hline & CIU's & CIAFS9 & 0.686 & 0030 & 0573 \\
\hline & Sources & CIAFS10 & 0.767 & 0.959 & 0.513 \\
\hline & & CIAFS11 & 0.771 & & \\
\hline & & CIAFS12 & 0.808 & & \\
\hline & & CIAFS13 & 0.774 & & \\
\hline & & CIAFS14 & 0.776 & & \\
\hline & & CIAFS15 & 0.594 & & \\
\hline & & CIAFS16 & 0.782 & & \\
\hline & & HP_CP1 & 0.898 & & \\
\hline & $\begin{array}{l}\text { Customer } \\
\text { persnective }\end{array}$ & HP_CP2 & 0.930 & 0929 & 0766 \\
\hline & (HP-CP) & HP_CP3 & 0.807 & 0.023 & \\
\hline & & HP_CP4 & 0.859 & & \\
\hline & & HP_FP1 & 0.814 & & \\
\hline & Financial & HP_FP2 & 0.791 & & \\
\hline & perspective & HP_FP3 & 0.790 & 0.923 & 0.706 \\
\hline Hotels' & (HP-FP) & HP_FP4 & 0.899 & & \\
\hline Performance & & HP_FP5 & 0.898 & & \\
\hline & Internal & HP_IPP1 & 0.826 & & \\
\hline & process & HP_IPP2 & 0.838 & 0.936 & 0.786 \\
\hline & perspective & HP_IPP3 & 0.942 & 0.950 & \\
\hline & (HP-IPP) & HP_IPP4 & 0.933 & & \\
\hline & & HP_LGP1 & 0.835 & & \\
\hline & and orowth & HP_LGP2 & 0.826 & 0.902 & 0.698 \\
\hline & & HP_LGP3 & 0.851 & & \\
\hline
\end{tabular}


After confirming the convergent validity, we examined the discriminant validity using the Fornell and Larcker (1981) approach. To what extent is a collection of items utilised to estimate a single construct, and to what extent is this estimate completed separately (Hair et al., 2014). To properly use this strategy, the correlation between the latent constructs must be larger than the square root of the AVE of each latent construct (Fornell and Larcker, 1981; Hair et al., 2014). As a result, one item was eliminated (CIAS16) in order to conform to Fornell and Larcker's requirements (1981). It can be assumed that discriminant validity has been proven completely because the square root of the AVE values is greater than in their own rows and columns. The data are summarised in Table 6, and the measurement model is depicted in Figure 4.

Table 6: Results of Discriminant Validity by "Fornell-Larcker Criterion"

\begin{tabular}{ccccccccc}
\hline Construct & CIA-S & CIA-T & CIU-S & CIU-T & $\begin{array}{c}\text { HP- } \\
\text { CP }\end{array}$ & $\begin{array}{c}\text { HP- } \\
\text { FP }\end{array}$ & $\begin{array}{c}\text { HP- } \\
\text { IPP }\end{array}$ & $\begin{array}{c}\text { HP- } \\
\text { LGP }\end{array}$ \\
\hline CIA-S & $\mathbf{0 . 7 4 1}$ & & & & & & & \\
CIA-T & 0.695 & $\mathbf{0 . 7 3 5}$ & & & & & & \\
CIU-S & 0.736 & 0.432 & $\mathbf{0 . 7 5 7}$ & & & & & \\
CIU-T & 0.721 & 0.717 & 0.667 & $\mathbf{0 . 7 4 9}$ & & & & \\
HP-CP & 0.528 & 0.357 & 0.512 & 0.499 & $\mathbf{0 . 8 7 5}$ & & & \\
HP-FP & 0.568 & 0.391 & 0.432 & 0.478 & 0.732 & $\mathbf{0 . 8 4 0}$ & & \\
HP-IPP & 0.445 & 0.320 & 0.479 & 0.499 & 0.847 & 0.743 & $\mathbf{0 . 8 8 7}$ & \\
HP-LGP & 0.435 & 0.262 & 0.449 & 0.519 & 0.648 & 0.606 & 0.791 & $\mathbf{0 . 8 3 5}$ \\
\hline
\end{tabular}

According to the findings, the recommended conceptualization of CIA-T and CIA-S for CIA, and CIA-FT and CIA-FS for CIU as reflecting second-order structures were supported. This methodology is in agreement with prior researches that have combined CIA and CIU to create a second-order approach such as Yap et al. (2014) and Yap et al. (2018). To identify and explain the whole performance of firms, the many dimensions construct (as second-order structures) were utilized instead of a single construct (HP-CP, HP-FP, HP-IPP, and HP-LGP) used in the studies of Kaplan and Norton (1992) and Mohammed et al. (2017) in this study. This research seeks to learn more about the correlation between CIA and CIU so that we can enhance our comprehension of how they are related to other variables. 


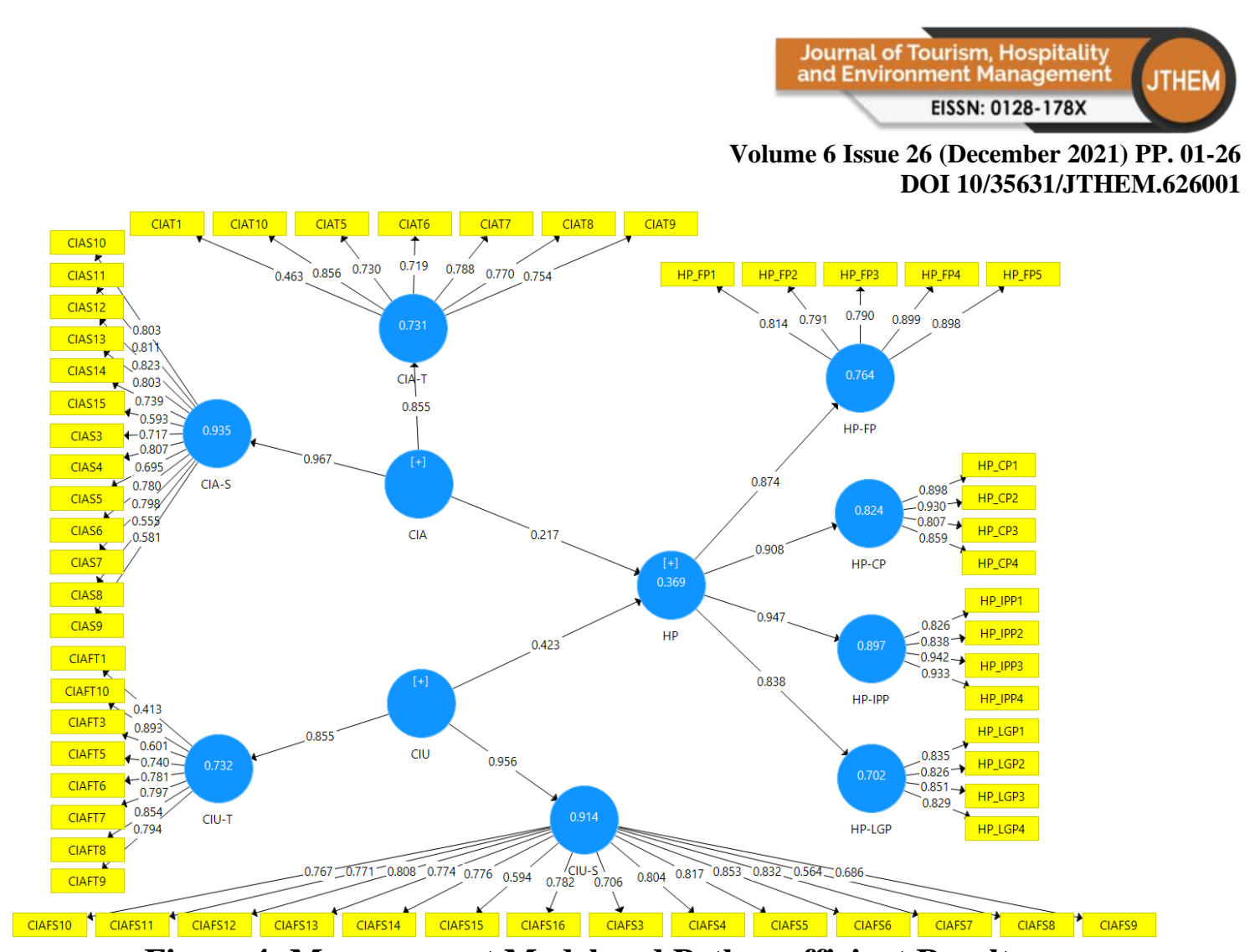

Figure 4: Measurement Model and Path-coefficient Results

\section{Structure-mode Valuation}

Once the model's validity and reliability had been confirmed, the hypothesized link was investigated using Smart-PLS 3.3.3. Figures $4 \& 5$, and Table 7 illustrate the results. Hair et al. (2014) notes that the important criterion for the structural model evaluation is R2, as the predictive PLS-SEM approach tries to illuminate the variance of the endogenous latent variables. So, R2, which is one of the primary objectives, should be placed in a high position. They also considered the R 2 value of $0.75,0.50$, and 0.25 , and arrived at the conclusion that these values were "high, moderate, and weak", respectively. In our study, R2 obtained a value of 0.369 using the PLS algorithm, and this value is a weak level. Figure 4 shows that the CIA and CIU approaches account for $40 \%$ of the variation in hotels' performance, which is in the weak range. using the blindfolding approach, the model was also assessed to see if it was of a high enough quality (Henseler et al., 2009). The Stone-Geisser test can be used to simulate soft modelling comparable to hand in glove, says Valerie (2012). "This test is computed through the formula $\mathrm{Q} 2=1$ - sum of squares of prediction errors (SSE)/sum of squares of observations (SSO)". When blindfolding is employed, the value of Q2 is derived by counting the number of cases in the data instead of the given omissions distance. If the value of Q2 is not a multiple of the given omissions distance, then the blindfolding method provides inaccurate values, and values from 5 to 10 should be used (Hair et al., 2014). Since this research utilised 7 as the value of $\mathrm{d}$ to represent the cross-validated redundancy methods for each dependent variable, the current research selected 7 as the value of d. According to Hair et al. (2014), if the crossredundancy value is larger than zero, the model has predictive value; otherwise, one cannot make any conclusions about the predictive relevance of the model. The cross-validated redundancy of hotels' performance was 0.214 , as shown in Table 9. Thus, it was concluded that the model's prediction quality is satisfactory.

Additionally, the effect size for the latent factors on the dependent variable was evaluated using f2 analysis, which is a complement to R2 (Chin, 2010). According to Cohen (2013), the effect sizes (big, medium, and small) for the predictive variables are represented by f 2 values of $(0.35$, 
Volume 6 Issue 26 (December 2021) PP. 01-26 DOI 10/35631/JTHEM.626001 0.15, and 0.02). As indicated in Table 8, it can conclude that, CIA and CIU have a small effect size with $(0.03$ and 0.11$)$ respectively on hotel performance.

Table 7: Hypothesis-Testing Results

\begin{tabular}{|c|c|c|c|c|c|}
\hline Hypotheses & $\begin{array}{c}\text { Path } \\
\text { coefficient }\end{array}$ & $\begin{array}{c}\text { Standard } \\
\text { error }\end{array}$ & $\begin{array}{c}\text { T } \\
\text { Statistics }\end{array}$ & $\begin{array}{c}\text { P- } \\
\text { Values }\end{array}$ & Results \\
\hline CIA -> HP & 0.217 & 0.089 & 2.443 & 0.015 & Supported \\
\hline CIU -> HP & 0.423 & 0.083 & 5.105 & 0.000 & Supported \\
\hline
\end{tabular}

Note: $* * *: p<0.01 ; * *: p<0.05 ; *: p<0.1$

Table 8: Effect Size $\left(\mathbf{F}^{2}\right)$

\begin{tabular}{cccc}
\hline Construct & $\mathbf{R}^{\mathbf{2}}$ & $\mathbf{F}^{\mathbf{2}}$ & Effect \\
\hline HP & 0.369 & & \\
\hline CIA & -- & 0.03 & Small Impact \\
CIU & -- & 0.11 & Small Impact
\end{tabular}

Table 9: Model's Prediction Relevance

\begin{tabular}{cccc}
\hline Total & SSO & SSE & $\begin{array}{c}\mathbf{Q}^{\mathbf{2}}(=\mathbf{1 -} \\
\text { SSE/SSO) }\end{array}$ \\
\hline Hotel's Performance & 3128.000 & 2459.490 & 0.214 \\
\hline
\end{tabular}

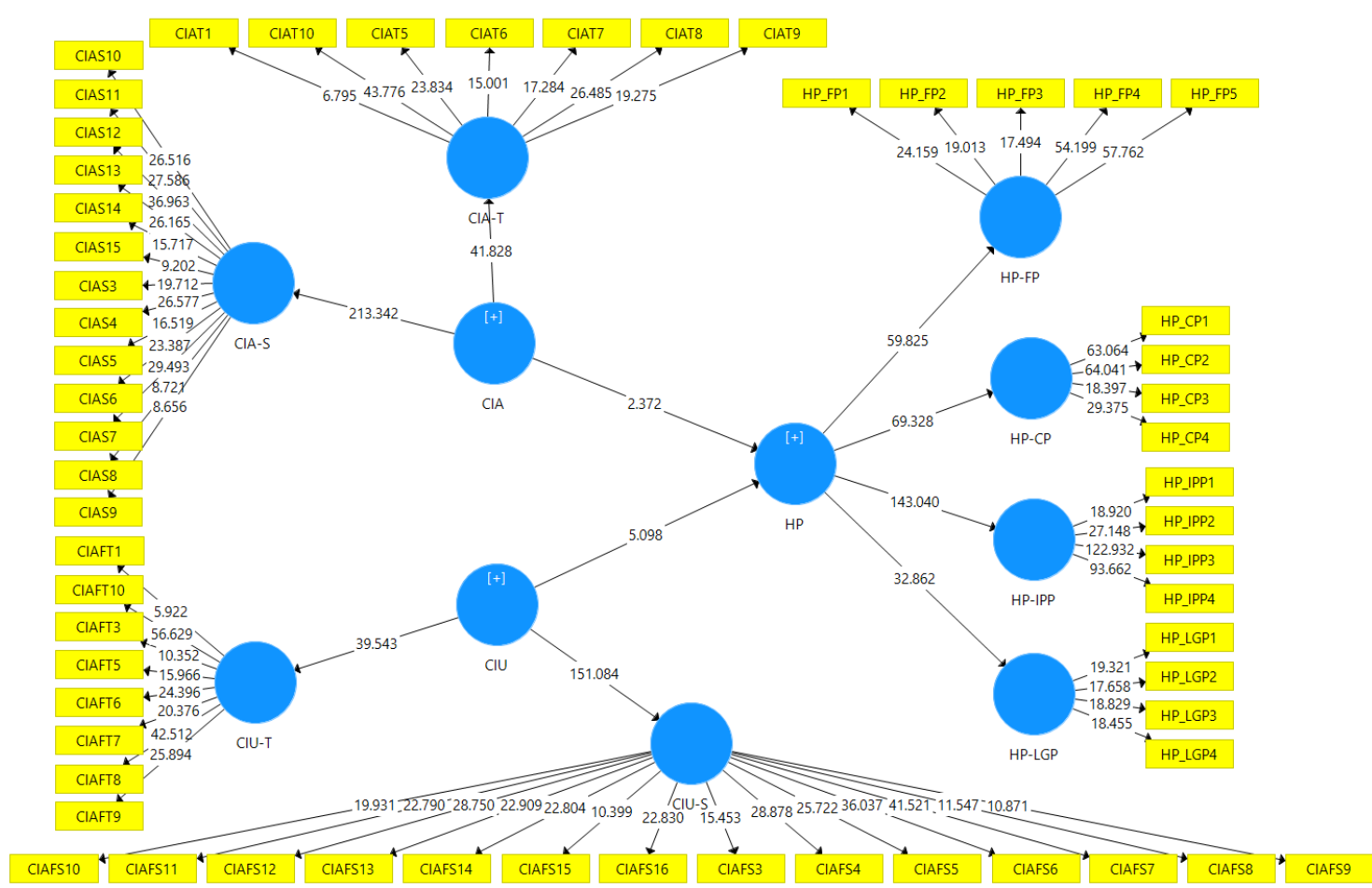

Figure 5: Hypothesis-Testing Results

\section{Discussion and Implications}

The hospitality industry is in desperate need of CI, particularly in the age of big data, where better CI practices would assist hotel managers in making better marketing decisions based on 


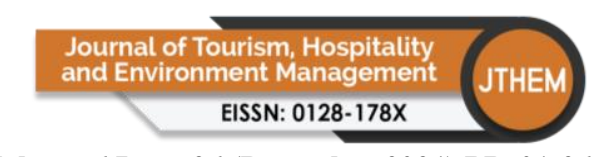

Volume 6 Issue 26 (December 2021) PP. 01-26 DOI 10/35631/JTHEM.626001

the quality of information, timely, and comprehensive data, resulting in a competitive advantage and improved hotel performance (Yan-li \& He-feng, 2015; Yan-Li \& He-feng, 2016; Salguero et al., 2019). As a result, the current study sought to ascertain the nature of CI practice at hotels in an emerging economy such as Malaysia. As well as to illustrate the relative importance of various CIA types and sources to marketing managers in Malaysian hotels. Furthermore, the study seeks to determine the impact of CIA and CIU on hotels' performance in Malaysia. To achieve the first goal, descriptive statistics were used, as it was discovered that half of the studied hotels practice CI informally, at a rate of 51 percent, and that the majority of Malaysian hotels began practicing CI five years ago, at a rate of 58.7 percent, while 37.5 percent began practicing CI ten years ago. The marketing department, on the other hand, was found to be the most interested in CI, with a percentage of 74.5 percent. Furthermore, 56 percent of hotels have one to five employees working for CI. On the other hand, regarding ranking the types and sources of CIA according to their relative importance to the marketing managers of Malaysian hotels, competitors and customers obtained a high level of importance with RII-values of (0.95 and 0.94) respectively, while the rest of the types obtained (mediumhigh) of importance level. Therefore, the five most important types of CIA to Malaysian hotel marketing managers can be arranged as follows: (1) competitors, (2) customers, (3) human resources, (4) socio-cultural, and (5) Global. Additionally, regarding to ranking the sources of CIA according to their relative importance to the marketing managers of Malaysian hotels, the internet and extranets, customers, electronic information services/intranets, business associates, newspapers and periodicals, and industry trade associations obtained a high level of importance with RII-values of $(0.91,0.88,0.87,0.84,0.83$ and 0.83$)$ respectively, while the rest of the sources obtained the medium to high levels importance values. Therefore, the five most important sources of CIA to Malaysian hotel marketing managers can be arranged as follows: (1) the internet and extranets, (2) customers, (3) electronic information services/intranets, (4) business associates, and (5) newspapers and periodicals, and industry trade associations, the types and sources are arranged in descending order from most important to least important. This demonstrates that marketing managers at Malaysian hotels have a thorough understanding of the various forms and sources of CIA, despite the fact that they perform CI in an informal manner. As a result, researchers saw that Malaysian hotel managers should make a greater effort to establish an official unit for CI, considering the critical role it plays in increasing hotel performance

The second objective of this study is to examine the effect of CIA and CIU on Malaysian hotels' performance. Because they are important dimensions of the CI in the era of massive data (Yap et al., 2018; Yin, 2018; Collovini et al., 2020). The empirical result reveals that the CIA has an impact on hotel performance $(\beta=0.217, \mathrm{t}=2.443, \mathrm{p}<0.01)$, as shown in Table 7 . As a result, $\mathrm{H} 1$ is acceptable. This conclusion means that hotels that seeking information acquisition via $\mathrm{CI}$ to assist its to evaluate the emerging trends in their business environments, major and potential threats, capabilities, and competitions to enhance competitiveness and effective hotels' performance (Ashrafi \& Ravasan, 2018; Yin, 2018; Asghari et al., 2020). As a result, hotels that practice CIA achieve better performance. Furthermore, the empirical result reveals that the CIU has an impact on hotel performance $(\beta=0.423, \mathrm{t}=5.105, \mathrm{p}<0.001)$, as shown in Table 7 . As a result, $\mathrm{H} 2$ is acceptable. This conclusion means that hotels that frequently seeking information acquisition via $\mathrm{CI}$ to assist its to evaluate the emerging trends in their business environments, major and potential threats, capabilities, and competitions to enhance competitiveness and effective hotels' performance (Ashrafi \& Ravasan, 2018; Yin, 2018; 


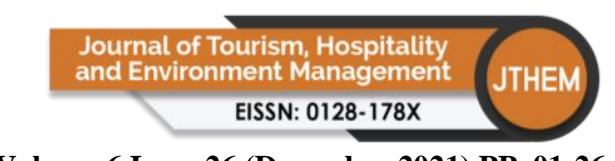

Volume 6 Issue 26 (December 2021) PP. 01-26 DOI 10/35631/JTHEM.626001 Asghari et al., 2020). As a result, hotels that frequently practice CIU achieve better performance.

In general, the results of this study proved that CIA and CIU affect the performance of hotels by $40 \%$, which means, the CIA and CIU practice account for $40 \%$ of the variation in hotels' performance, which is in the weak range. This result is in line with the previous studies examining the impact of the CIA on firms' performance such as Yap et al. (2014) and Yap et al. (2018). Although this result confirms the significant effect of CIA and CIU on hotels" performance, there is limited research in the hotel sector such as Yap et al. (2014), Yan-Li and He-feng (2016), and Köseoglu et al. (2020).

\section{Conclusion and Limitations}

This study is one of the first studies that look at the effect of practice CIA and CIU on hotels' performance in Malaysia. The researchers also conducted an additional investigation about the nature of CI practise in Malaysian hotels, and the relative importance of various CIA types and sources to marketing managers in Malaysian hotels. The findings from the study showed that the CIA and CIU practices were strongly linked to shotels' performance. Additional evidence shows that the CIU practice is the most relevant, and followed by the CIA practice on hotels' performance. Moreover, the results showed that although half of the Malaysian hotels were practicing CI informally, the hotel marketing managers have high and medium interest levels for most types and sources of CI in Malaysia. Where the five most important types of CIA to Malaysian hotel marketing managers were arranged as follows: (1) competitors, (2) customers, (3) human resources, (4) socio-cultural, and (5) Global, as well as the five most important sources of CIA to Malaysian hotel marketing managers were arranged as follows: (1) the internet and extranets, (2) customers, (3) electronic information services/intranets, (4) business associates, and (5) newspapers and periodicals, and industry trade associations. These findings have major implications for understanding how hotels improve their performance. The observed difference in the shift from survival mode to hotels' growth is most clearly demonstrated by a combination of the CIA and CIU.

This study has limitations, including the difficulty of acquiring data on all hotels in all of Malaysia's states, as well as the influence of the Corona pandemic, which prevented researchers from gathering additional data. Additionally, this study examined the association between hotel performance in Malaysia and the CIA and CIU. This enables future research to focus on new dimensions of CI and the role of mediating variables in the relationship between CI and hotel performance, with increasing response rates. The second shortcoming is that existing research is hotels industry-specific. Future research should consequently focus on Malaysia's other industry. Thirdly, this probe is being conducted in Malaysia. Thus, future studies can repeat the findings in different countries in order to generalise the findings.

\section{References}

Ahn, J., \& Kwon, J. (2020). Green hotel brands in Malaysia: perceived value, cost, anticipated emotion, and revisit intention. Current Issues in Tourism, 23(12), 1559-1574.

Asghari, S., Targholi, S., Kazemi, A., Shahriyari, S., \& Rajabion, L. (2020). A new conceptual framework for identifying the factors influencing the effectiveness of competitive intelligence. Competitiveness Review: An International Business Journal, DOI: 10.1108/CR-05-2019-0054. 


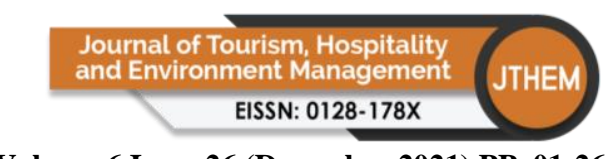

Volume 6 Issue 26 (December 2021) PP. 01-26

DOI 10/35631/JTHEM.626001

Ashrafi, A., \& Ravasan, A. Z. (2018). How market orientation contributes to innovation and market performance: the roles of business analytics and flexible IT infrastructure. Journal of Business \& Industrial Marketing, 33(7), 970-983.

Breakspear, A., 2013. A new definition of intelligence. Intelligence National Security, 28 (5), 678-693.

Calof, J. (2017). Canadian competitive intelligence practices-a study of practicing strategic and competitive intelligence professionals Canadian members. Foresight, 19(6), 577 589.

Calof, J., \& Sewdass, N. (2020). On the relationship between competitive intelligence and innovation. Journal of Intelligence Studies in Business, 10(2), 32-43.

Calof, J., Arcos, R., \& Sewdass, N. (2018). Competitive intelligence practices of European firms. Technology Analysis \& Strategic Management, 30(6), 658-671.

Cavallo, A., Sanasi, S., Ghezzi, A., \& Rangone, A. (2020). Competitive intelligence and strategy formulation: connecting the dots. Competitiveness Review: An International Business Journal, 31: 250-75.

Cheangtawee, P., Paopun, N., \& Fongsuwan, W. (2020). The Development of Key Performance Indicators for E-Commerce in Hotel Businesses Using Balanced Scorecard. Proceedings of the Fourth International Conference on eBusiness, November (19-20), Bangkok, Thailand.

Chin, W. W. (2010). How to write up and report PLS analyses. In: Vinzi, V.E., Chin, W. W., Henseler, J. \& Wang, H. (Eds.), Handbook of Partial Least Squares, first ed. Springer, Berlin, pp. 655-690.

Collovini, S., Gonçalves, P. N., Cavalheiro, G., Santos, J., \& Vieira, R. (2020, March). Relation Extraction for Competitive Intelligence. In International Conference on Computational Processing of the Portuguese Language (pp. 249-258). Springer, Cham, Nature Switzerland.

Daft, R. L., Sormunen, J., \& Parks, D. (1988). Chief executive scanning, environmental characteristics, and company performance: An empirical study. Strategic Management Journal, 9(2), 123-139.

Falahat, M., Ramayah, T., Soto-Acosta, P., \& Lee, Y. Y. (2020). SMEs internationalization: The role of product innovation, market intelligence, pricing and marketing communication capabilities as drivers of SMEs international performance. Technological Forecasting and Social Change, 152, 1-7.

Fornell, C. \& Larcker, D. (1981). Evaluating structural equation models with unobservable variables and measurement error. Journal of Marketing Research, 18(1), 39-50.

Gheysari, K. (2015). Evaluating influence of using the internet for competitive intelligence and strategic benefits (Case study: food industry companies). Journal UMP Social Sciences and Technology Management, 3(3), 340-347.

Hair, J. F., Hult, G. T. M., Ringle, C. M., \& Sarstedt, M. (2014). A primer on partial least squares structural equation modeling (PLS-SEM). Thousand Oaks: Sage Publications. Retrieved from http://www.sagepub.com/books/Book237345

Hair, J. F., Risher, J. J., Sarstedt, M., \& Ringle, C. M. (2019). When to use and how to report the results of PLS-SEM. European Business Review, 31(1), 2-24.

Hair, J.F., Hult, G.T.M., Ringle, C.M. and Sarstedt, M. (2017), A Primer on Partial Least Squares Structural Equation Modeling (PLS-SEM), Sage, Thousand Oaks, CA.

Hanif, N., Arshed, N., \& Farid, H. (2021) Competitive intelligence process and strategic performance of banking sector in Pakistan. J. Business Information Systems, 1-24. 


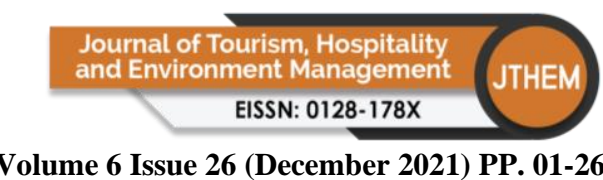

Volume 6 Issue 26 (December 2021) PP. 01-26

DOI 10/35631/JTHEM.626001

Hendar, H., Ratnawati, A., Ab Razak, W. M. W., \& Abdullah, Z. (2020). Market intelligence on business performance: The mediating role of specialized marketing capabilities. Journal of Intelligence Studies in Business, 1(1), 42-58.

Henseler, J., Ringle, C. M., \& Sarstedt, M. (2015). A new criterion for assessing discriminant validity in variance-based structural equation modeling. Journal of the academy of marketing science, 43(1), 115-135.

Johnson, J. W., \& LeBreton, J. M. (2004). History and use of relative importance indices in organizational research. Organizational research methods, 7(3), 238-257.

Kaplan, R. S., \& Norton, D. P. (1992). The balanced scorecardMeasures that drive performance. Harvard Business Review, 70(1), 71-79.

Köseoglu, M. A., Mehraliyev, F., Altin, M., \& Okumus, F. (2020). Competitor intelligence and analysis (CIA) model and online reviews: integrating big data text mining with network analysis for strategic analysis. Tourism Review, DOI: 10.1108/TR-102019-0406.

Köseoglu, M. A., Morvillo, A., Altin, M., De Martino, M., \& Okumus, F. (2019). Competitive intelligence in hospitality and tourism: a perspective article. Tourism Review, 28, 690710.

Köseoglu, M. A., Ross, G., \& Okumus, F. (2016). Competitive intelligence practices in hotels. International Journal of Hospitality Management, 53 (-), 161-172.

Lutz, C. J., \& Bodendorf, F. (2020). Analyzing industry stakeholders using open-source competitive intelligence-a case study in the automotive supply industry. Journal of Enterprise Information Management, 33(3), 579-599.

Madureira, L., Popovič, A., \& Castelli, M. (2021). Competitive intelligence: A unified view and modular definition. Technological Forecasting and Social Change, 173, 121086.

MAH, Malaysia, 31 December, 2018. Available from: http://www.hotels.org.my/directories.html.

Marin, J., \& Poulter, A. (2004). Dissemination of competitive intelligence. Journal Of Information Science, 30(2), 165-180.

Maritz, R., \& du Toit, A. (2018). The practice turn within strategy: Competitive intelligence as integrating practice. South African Journal of Economic and Management Sciences, 21(1), 1-14.

Markovich, A., Efrat, K., Raban, D. R., \& Souchon, A. L. (2019). Competitive intelligence embeddedness: Drivers and performance consequences. European Management Journal, (-), 1-11.

Mohamad, N. H., Shabani, M., \& Woods, P. C. (2018). Competitive Intelligence Awareness in Creative Multimedia Industry in Malaysia. Advanced Science Letters, 24(2), 10221026.

Mohammed, A. A., Rashid, B. B., \& Tahir, S. B. (2017). Customer relationship management and hotel performance: the mediating influence of marketing capabilities-evidence from the Malaysian hotel industry. Information Technology \& Tourism, 17(3), 335361.

Muller, M. L. (2004). The development of competitive intelligence (CI) in South Africa with special reference to the CI practices in a pharmaceutical company. Published $\mathrm{PhD}$ thesis, The NorthWest University, South Africa.

Oraee, N., Sanatjoo, A., \& Ahanchian, M. R. (2020). The competitive intelligence diamond model with the approach to standing on the shoulders of giants. Library \& Information Science Research, 42(2), 1-12. 


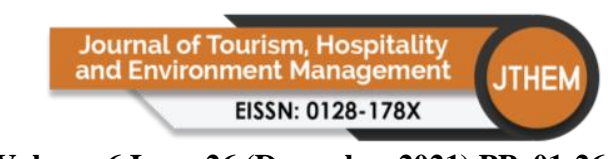

Volume 6 Issue 26 (December 2021) PP. 01-26 DOI 10/35631/JTHEM.626001

Pellissier, R., \& Nenzhelele, T. E. (2013). Towards a universal competitive intelligence process model. South African Journal of Information Management, 15(2), 1-7.

Saayman, A., Pienaar, J., de Pelsmacker, P.J., Viviers, W., Cuyvers, L., Muller, M.-L., \& Jegers, M. (2008). Competitive Intelligence: Construct exploration, validation and equivalence. Aslib Proceedings: New Information Perspectives, 60(4), 383-411.

Saleh, M. H. M., Azmin, A. A., \& Saraih, U. N. EFFECT OF MARKETING ETHICS AS A MODERATE ON THE RELATIONSHIP BETWEEN MARKET ORIENTATION AND SME PERFORMANCE: EVIDENCE FROM SAUDI ARABIA. International Journal of Entrepreneurship and Management Practises (IJEMP), 14(4), 13-29.

Saleh, M. H. M., Azmin, A. A., \& Saraih, U. N. THE EFFECT OF MARKETING ETHICS AS A MODERATOR ON THE RELATIONSHIP BETWEEN CUSTOMER ORIENTATION AND SMES PERFORMANCE IN SAUDI ARABIA. Advanced International Journal of Business, Entrepreneurship and SME's (AIJBES), 8(3), 119138.

Saleh, Moad Hamod M., Adi Anuar Azmin, and Ummi Naiemah Saraih. "THE EFFECTS OF MARKET ORIENTATION, PRODUCT INNOVATION AND MARKETING ETHICS ON FIRM PERFORMANCE: A THEORETICAL FRAMEWORK.". International Journal of Innovation and Industrial Revolution (IJIREV), 7(3), 31-47.

Salguero, G. C., Gámez, M. Á. F., Fernández, I. A., \& Palomo, D. R. (2019). Competitive Intelligence and Sustainable Competitive Advantage in the Hotel Industry. Sustainability, 11(6), 1-12.

Salguero, G. C., Resende Jr, P. C., \& Fernández, I. A. (2017). Proposal of an assessment scale in competitive intelligence applied to the tourism sector. Journal of Intelligence Studies in Business, 7(2), 38-47.

SCIP (2009). Social Citizenship Indicator Program database homepage. Available at Available at https://dspace.it.su.se/dspace/handle/10102/7. (last accessed 18 January 2009).

Sekaran, U. and Bougie, R. (2016), Research Methods for Business: A Skill Building Approach, John Wiley \& Sons, Queensland.

Seyyed-Amiri, N. A. D. E. R., Shirkavand, S., Chalak, M., \& Rezaeei, N. (2017). Competitive intelligence and developing sustainable competitive advantage. AD-Minister, 30(-), 173-194.

Shi, G., Mou, X., \& Wan, X. (2009, December). Designing a network acquisition system of competitive intelligence. In 2009 Eighth IEEE International Conference on Dependable, Autonomic and Secure Computing (pp. 686-689). IEEE, Chengdu, China.

Silva, P. M. (2021). Examination in B2B trade show: the effects of competitive intelligence and the information management system on the exhibitor's marketing strategy. Journal of Marketing Analytics, 1-14.

Sin, K. Y., \& Jusoh, M. S. (2019). Identifying and Prioritizing Research Gaps in Studies related to Total Quality Management on Competitive Advantage in Malaysian Hotel Industries. INTERNATIONAL JOURNAL OF ACADEMIC RESEARCH IN BUSINESS AND SOCIAL SCIENCES, 9(5), 335 - 349.

Søilen, K. S. (2017). Why care about competitive intelligence and market intelligence? The case of Ericsson and the Swedish Cellulose Company. Journal of Intelligence Studies in Business, 7(2), 27-39.

Tao, Q., \& Prescott, J. E. (2000). China: Competitive intelligence practices in an emerging market environment. Competitive Intelligence Review, 11(4), 65-78. 


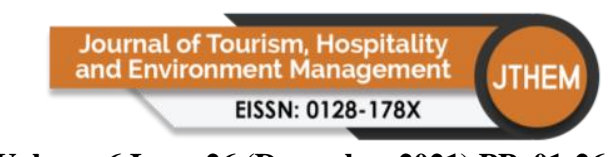

Volume 6 Issue 26 (December 2021) PP. 01-26 DOI 10/35631/JTHEM.626001

Tej Adidam, P., Banerjee, M., \& Shukla, P. (2012). Competitive intelligence and firm's performance in emerging markets: an exploratory study in India. Journal of Business \& Industrial Marketing, 27(3), 242-254.

Teo, T. S., \& Choo, W. Y. (2001). Assessing the impact of using the Internet for competitive intelligence. Information \& Management, 39(1), 67-83.

Tourism Malaysia (2020) Tourism Malaysia-statistics. Retrieved 10 Jul 2020 from: https://www.tourism.gov.my/statistics.

UNWTO. (2018), Tourism Highlight 2018, World Tourism Organization. Retrieved August, 2018 from: https://www.e-unwto.org/doi/book/10.18111/9789284419876

Valerie, F. (2012). Re-discovering the PLS approach in management science. M@n@gement,15(1),101-123.

Vugec, D. S., Vukšić, V. B., Bach, M. P., Jaklič, J., \& Štemberger, M. I. (2020). Business intelligence and organizational performance. Business Process Management Journal, DOI 10.1108/BPMJ-08-2019-0342.

Wamba, S. F., Akter, S., Trinchera, L., \& De Bourmont, M. (2019). Turning information quality into firm performance in the big data economy. Management Decision, 57(8), 1756-1783.

Wu, S. I., \& Lu, C. L. (2012). The relationship between CRM, RM, and business performance: A study of the hotel industry in Taiwan. International Journal of Hospitality Management, 31(1), 276-285.

Yadegaridehkordi, E., Nilashi, M., Shuib, L., Nasir, M. H. N. B. M., Asadi, S., Samad, S., \& Awang, N. F. (2020). The impact of big data on firm performance in hotel industry. Electronic Commerce Research and Applications, (40), 1-33.

Yan-Li, B., \& He-feng, H. (2015, December). Research on evaluation index system of tourist hotels' competitive intelligence ability. In Computer Science and Network Technology (ICCSNT), 2015 4th International Conference on (Vol. 1, pp. 495-499). IEEE, December 19-20, 2015, Harbin, China.

Yan-Li, B., \& He-feng, H. (2016, October). Framework and management of competitive intelligence system for tourist hotels in the era of big data. In Computer and Communications (ICCC), 2016 2nd IEEE International Conference on (pp. 60-64). IEEE, Oct. 14-17, 2016, Chengdu, China, 60-64.

Yap, C. S., \& Rashid, M. Z. A. (2011). Acquisition and strategic use of competitive intelligence. Malaysian Journal of Library \& Information Science, 16(1), 125-136.

Yap, C. S., Cheng, B. L., \& Choe, K. L. (2014). Web 2.0 as a tool for market intelligence acquisition in the Malaysian hotel industry. Information Research, 19(4), 55-70

Yap, C. S., Cheng, B. L., Mohamad Hussain, N., \& Ahmad, R. (2018). Innovativeness, market intelligence practices, and firm performance of small-and medium-sized tour operators. Tourism and Hospitality Research, 18(2), 143-151.

Yap, C. S., Rashid, M. Z. A., \& Sapuan, D. A. (2012). Organizational strategy and competitive intelligence practices in Malaysian public listed companies. Information Research, 17(4), 1-13.

Yap, C. S., Rashid, M. Z. A., \& Sapuan, D. A. (2013). Strategic uncertainty and firm performance: The mediating role of competitive intelligence practices. Journal of Information \& Knowledge Management, 12(04), 1-14.

Yin, C. Y. (2018). Measuring organizational impacts by integrating competitive intelligence into executive information system. Journal of Intelligent Manufacturing, 29(3), 533547. 
Volume 6 Issue 26 (December 2021) PP. 01-26 DOI 10/35631/JTHEM.626001

Zikmund, W. G. (2003). Sample designs and sampling procedures. Business Research Methods, 7(2), 368-400.

Zikmund, W. G., Babin, B. J., Carr, J. C., \& Griffin, M. (2013). Business research methods (9th edition). SOUTH-WESTERN, USA: Cengage Learning. 